\title{
Equidade em saúde: o caso da tuberculose na comunidade de bolivianos no município de São Paulo
}

Vanessa Nogueira Martinez

Dissertação apresentada ao Programa de Pós-Graduação em Saúde Pública da Faculdade de Saúde Pública da Universidade de São Paulo para obtenção do título de Mestre em Saúde Pública

Área de Concentração Epidemiologia

Orientador: Prof. Dr. Eliseu Alves Waldman

São Paulo

2010 
É expressamente proibida a comercialização deste documento, tanto na sua forma impressa como eletrônica. Sua reprodução total ou parcial é permitida exclusivamente para fins acadêmicos e científicos, desde que na reprodução figure a identificação do autor, título, instituição e ano da dissertação. 
Este trabalho contou com o apoio da Fundação de Amparo a Pesquisa (FAPESP) (Processo. $n^{\circ}$ 2009/06524-6). 


\section{Agradecimentos}

Ao Prof. Dr. Eliseu Alves Waldman por sua orientação, paciência, dedicação e pelos seus ensinamentos e incentivos constantes.

A Sumie Matai de Figueiredo e Naomi Kawaoka Komatsu pela colaboração e atenção durante a coleta de dados, sem os quais esse trabalho não seria possível.

Aos auxiliares de enfermagem das Unidades Básicas de estudo: Márcia, Lívia, Ângelo, Neiva e Claudinei pelo apoio, paciência e por tornar possível a proximidade entre mim e os imigrantes bolivianos em tratamento.

Aos enfermeiros coordenadores do Programa de TB e gerentes das UBS de estudo, Cíntia, Maria Ângela, Célia, Walkíria, Terezinha, Karina e Wagner Urias pela confiança e apoio ao estudo realizado.

A Dra. Claudia Valencia Montero e aos Professores Doutores Péricles Alves Nogueira e Ivan França Júnior pelas valiosas contribuições no exame de qualificação e pré-banca.

Aos imigrantes bolivianos que participaram voluntariamente desse estudo pela confiança em mim depositada.

A Coordenação de Vigilância em Saúde da Secretaria Municipal de Saúde de São Paulo (COVISA) pelos dados cedidos.

A família e amigos pela compreensão e apoio.

A CAPES e FAPESP pelo suporte financeiro 
"Jamais considere seus estudos como uma obrigação, mas como uma oportunidade invejável para aprender a conhecer a influência libertadora da beleza do reino do espírito, para seu prazer pessoal e para proveito da comunidade à qual seu futuro trabalho pertencer".

Albert Einstein

Na epidemiologia um passo essencial no estudo de uma doença é "descrever precisamente sua ocorrência na população”.

John P. Fox

"Falar em mobilidade humana significa abordar a questão dos excluídos da nossa sociedade. As pessoas cada vez mais se deslocam por se sentirem excluídas dos benefícios e recursos disponíveis que, em princípio, deveriam ser acessíveis a todos”.

Ir. Rosita Milesi Pe.Virgílio Leite Uchoa 


\section{Resumo:}

Objetivo: Descrever o comportamento da tuberculose (TB) na comunidade boliviana residente em quatro distritos do município de São Paulo (MSP), Belém, Bom Retiro, Brás e Pari, no período de 1998 a 2008, analisar seu possível impacto na tendência dessa doença e investigar possíveis disparidades em relação ao acesso aos serviços e na qualidade do atendimento entre bolivianos e brasileiros. Metodologia: Estudo descritivo de casos notificados de TB entre migrantes bolivianos. Os dados foram obtidos junto à vigilância da TB do MSP. As variáveis de interesse foram: características sócio-demográficas, aspectos diagnósticos, clínicos e terapêuticos, comportamentais, co-morbidades e indicadores de acesso aos serviços e de qualidade do atendimento. A análise foi efetuada comparando a as variáveis de interesse entre pacientes de nacionalidade boliviana e brasileira residentes nos mesmos distritos. Para a comparação de proporções aplicamos o teste do qui-quadrado ou teste exato de Fisher e para médias o teste de Kruskal-Wallis. Resultados: Foram notificados 2434 casos de TB nos distritos estudados, dos quais 67,5 \%, 30,4\% e 2,1\% eram, respectivamente de nacionalidade brasileira, boliviana e outras; a participação boliviana foi crescente no período, elevando-se de $15 \%$ para $53 \%$ dos casos; observando-se uma queda de $43,5 \%$ no número absoluto de casos entre os brasileiros e um incremento de $250 \%$ entre bolivianos. A incidência na área de estudo em 2008 era 3,5 vezes maior do que a verificada, em média, no MSP. Comparados aos brasileiros os bolivianos eram mais jovens (média: 26 versus 39 anos; $p<=0,0001$ ) e a prevalência de desemprego entre eles era mais baixa $(2,4 \%$ versus $10,4 \% ; p<0,0001)$. Para o período de 2006 a 2008, os bolivianos apresentam taxas mais elevada de cura $(70,9 \%$ versus $62,1 \% ; p<0,001)$ e de tratamento supervisionado $(81,9 \%$ versus $62,2 \% ; p<0,001)$ e menores de história de TB no passado $(6,9 \%$ versus $16,9 \% ; p<0,0001$ ), abandono de tratamento (16,9\% versus $22,4 \%$; $\mathrm{p}<0,001)$, de letalidade por TB $(1,6 \%$ versus $4,8 \% ; \mathrm{p}<0,001)$ e de recidiva $(4,9 \%$ versus $9,2 \% ; p<0,001)$. A prevalência de co-morbidades era mais baixa entre bolivianos. Em torno de $88 \%$ dos casos de ambas as nacionalidades o diagnóstico e o tratamento foi efetuado em serviços públicos de saúde. Conclusão: A TB mostrou-se um relevante problema entre bolivianos, contribuído para a manutenção de elevada incidência na área de estudo, justificando estratégias específicas de intervenção. Os resultados sugerem que o cumprimento das diretrizes do Sistema Único de Saúde, de acesso universal aos serviços constitui instrumento efetivo de promoção da equidade em saúde.

Palavras chaves: Tuberculose, imigrantes latino-americanos, epidemiologia, eqüidade em saúde, políticas públicas. 


\begin{abstract}
Objective: Describing the tuberculosis in the bolivian community resident in the districts of Belém, Bom Retiro, Bras and Pari, located in the municipality of São Paulo (MSP), in the period 1998 to 2008, analyze its possible difference in relation to access services and quality of health care among bolivians and brazilians. Methods: Descriptive study of notified cases of TB among bolivian immigrants. The data are obtained from the TB surveillance of the MSP. The variables of interest were socio-demographic characteristics, diagnostic aspects, clinical and therapeutical, behavioral, comorbidities and indicators of access to services and quality of care. The analysis was performed comparing the variables between bolivians and brazilians patients residing in the same districts. For comparison of proportion was applied the chi-square test or Fisher exact test and for means the Kruskal-Wallis test. Results: Were reported 2434 TB cases in districts studied, whom $67,5 \%, 30,4 \%$ e $2,1 \%$ were respectively brazilians, bolivians and others nationalities; the bolivian participation increased in the period, rise from $15 \%$ to $53 \%$ of all cases, observing a drop of $43,5 \%$ in the absolute numbers of cases among the brazilians and a increase of $250 \%$ among bolivians. The incidence in study area in 2008 was 3,5 times greater than that seen on average in MSP. Compared to brazilians, bolivians were younger (mean: 26 versus 39 years, $\mathrm{p}=0.0001$ and the prevalence of unemployment was lowest $(2,4 \%$ versus $10,4 \%, p<0,0001$. In 2006 to 2008 , bolivians have higher rates of cure $(70,9$ versus $62,1 \%, p<0,001)$ and supervised treatment $(81,9 \%$ versus $62,2 \%)$, and lower rates of TB in past $(6,9 \%$ versus $16,9 \%$, $\mathrm{p}<0,0001)$, neglect $(16,9 \%$ versus $22,4 \%, p<0,001)$, TB mortality $(1,6 \%$ versus $4,8 \%, p<0,001)$ and relapse $(4,9 \%$ versus $9,2 \%, p<0,001)$. The prevalence of comorbidities was lower among bolivians. Around $88 \%$ of cases of both nationalities the diagnosis and treatement was done in public health services. Conclusions: The TB is significant problem among bolivians, contributing to the maintenance of high incidence in the study area, justifying specific strategies of intervention. The results suggest that compliance with the guidelines of Sistema Único de Saude of universal access to services is an effective instrument for promoting equity in health.
\end{abstract}

Key words: Tuberculosis, Latin- American immigrants, epidemiology, health equity, public policies. 


\section{SUMÁRIO}

1. INTRODUÇÃ

Direitos humanos e imigração.......................................... 14

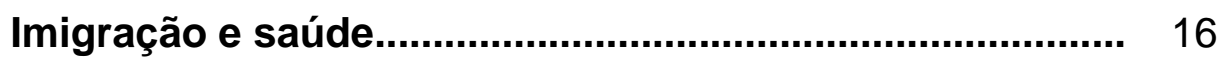

A tuberculose em imigrantes.............................................. 18

Imigração boliviana em São Paulo..................................... 20

Tuberculose na América Latina........................................ 21

Tuberculose no Brasil...................................................... 22

Tuberculose na Bolívia.................................................... 24

Tuberculose em São Paulo................................................ 25

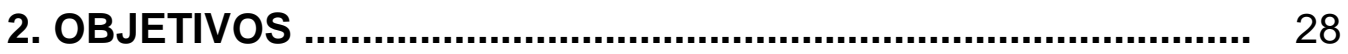

3. MATERIAL E MÉTODOS....................................................... 29

Delineamento de estudo …............................................. 29

Área e população de estudo ............................................ 29

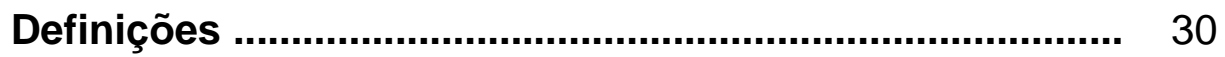

Critérios de inclusão e exclusão ......................................... 30

Fonte de dados ……...................................................... 31

Variáveis de estudo ...................................................... 31

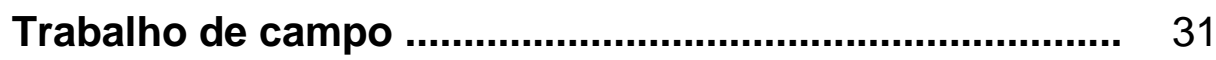

Preparação do banco de dados .................................... 32

Análise dos dados .......................................................... 32

Aspectos éticos da pesquisa............................................ 33

4. RESULTADOS …….......................................................... 34

Caracterização dos bolivianos em tratamento em 2009....... 50 


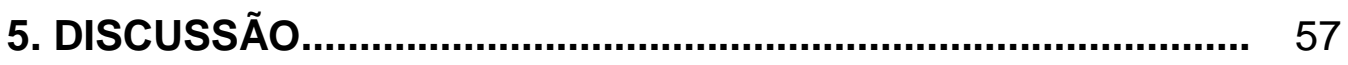

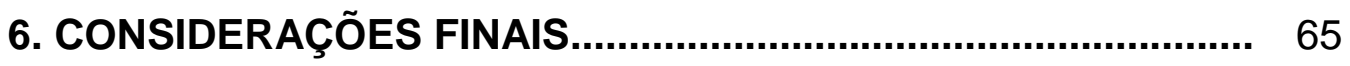

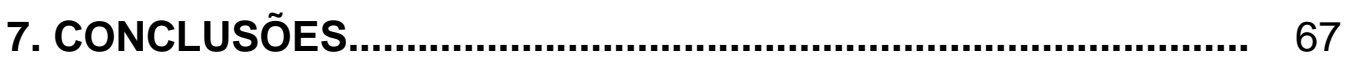

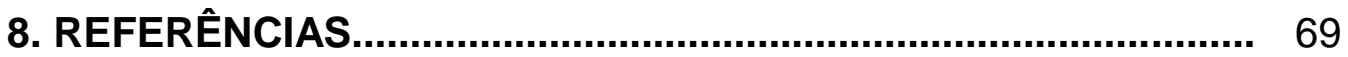

9. ANEXOS

Apêndice I: Questionário aplicado aos imigrantes bolivi- $\quad 78$ anos em tratamento nas UBS de estudo

Apêndice II: Consentimento livre e esclarecido.................. 83

Anexo I: Termo de responsabilidade.................................. 85

Anexo II: Comitê de ética em pesquisa-COEP/FSP........... 86

Apêndice III: Taxa de incidência de tuberculose nos distritos administrativos do Belém, Bom Retiro, Brás e Pari. Município de São Paulo. 1998 a 2005.

10. INFORMAÇÕES CURRICULARES........................................ 88 


\section{LISTA DE TABELAS}

Tabela 1: Casos notificados de TB por todas as formas e para todas as idades, segundo ano de diagnóstico e nacionalidade. Distritos do Belém, Bom Retiro, Brás e Pari. Município de São Paulo. 1998 a 2008.

Tabela 2: Casos notificados de TB por todas as formas e para todas as idades, segundo ano do diagnóstico, distrito de residência e nacionalidade. Município de São Paulo. 2006 a 2008.

Tabela 3: Casos notificados de TB por todas as formas e idades, segundo características sócio-demográficas. Distritos do Belém, Bom Retiro, Brás e Pari. Município de São Paulo. 1998 a 2008.

Tabela 4a: Casos notificados de TB por todas as formas e para todas as idades, segundo nacionalidade e a história pregressa da doença. Distritos do Belém, Bom Retiro, Brás e Pari. Município de São Paulo. 1998 a 2005.

Tabela 4b: Casos notificados de TB por todas as formas e para todas as idades, segundo nacionalidade e a história pregressa da doença. Distritos do Belém, Bom Retiro, Brás e Pari. Município de São Paulo. 2006 a 2008.

Tabela 5a: Casos notificados de TB de todas as formas e para todas as idades, segundo a nacionalidade e história atual da doença. Distritos do Belém, Bom Retiro, Brás e Pari. Município de São Paulo. 1998 a 2005. .

Tabela 5b Casos notificados de TB de todas as formas e para todas as idades, segundo a nacionalidade e história atual da doença. Distritos do Belém, Bom Retiro, Brás e Pari. Município de São Paulo. 2006 a 2008.

Tabela 6: Casos notificados de tuberculose por todas as formas e para todas as idades, segundo nacionalidade, esquema terapêutico e local de diagnóstico. Distritos do Belém, Bom Retiro, Brás e Pari. Município de São Paulo. 1998 a 2005. 
Tabela 7: Casos de tuberculose por todas as formas e para todas as idades, segundo nacionalidade e aspectos relativos ao tratamento. Distritos do Belém, Bom Retiro, Brás e Pari. Município de São Paulo. 2006 a 2008.

Tabela 8a: Casos notificados de TB por todas as formas e para todas as idades segundo nacionalidade e co-morbidades. Distritos do Belém, Bom Retiro, Brás e Pari. Município de São Paulo. 1998 a 2005.

Tabela 8b: Casos notificados de TB por todas as formas e para todas as idades segundo nacionalidade e co-morbidades. Distritos do Belém, Bom Retiro, Brás e Pari. Município de São Paulo. 2006 a 2008.

Tabela 9: Distribuição de casos de TB por todas as causas e para todas as idades, segundo nacionalidade e histórico de internações por TB. Distritos do Belém, Bom Retiro, Brás e Pari. Município de São Paulo. 1998 a 2005.

Tabela 10: Casos de tuberculose em imigrantes bolivianos ${ }^{\star}$ em tratamento em Unidades Básicas de Saúde, segundo características da residência. Distritos do Belém, Bom Retiro, Brás e Pari. Município de São Paulo, 2009.

Tabela 11: Casos de tuberculose em imigrantes bolivianos* em tratamento em Unidades Básicas de Saúde, segundo histórico da TB atual. Distritos do Belém, Bom Retiro, Brás e Pari. Município de São Paulo, 2009.

Tabela 12: Casos de tuberculose em imigrantes bolivianos ${ }^{*}$ em tratamento nas Unidades Básicas de Saúde, segundo sintomas referidos. Distritos do Belém, Bom Retiro, Brás e Pari. Município de São Paulo, 2009.

Tabela 13: Casos de tuberculose em imigrantes bolivianos* em tratamento nas Unidades Básicas de Saúde, segundo o tipo de contatos. Distritos do Belém, Bom Retiro, Brás e Pari. Município de São Paulo, 2009.

Tabela 14: Casos de tuberculose em imigrantes bolivianos* em tratamento nas Unidades Básicas de Saúde, segundo co-morbidades e história de prisão no passado. Distritos do Belém, Bom Retiro, Brás e Pari. Município de São Paulo, 2009. 


\section{SIGLAS UTILIZADAS}

CMDH: Comissão Municipal de Direitos Humanos

COVISA: Coordenação de Vigilância em Saúde

DOTS: Tratamento diretamente observado

DPOC: Doença Pulmonar Obstrutiva Crônica

IDH: Índice de desenvolvimento humano

M. tuberculosis: Mycobacterium tuberculosis

MS: Ministério da Saúde

MSP: Município de São Paulo

OMS: Organização Mundial da Saúde

PCT: Plano de Controle da Tuberculose

PNCT: Plano Nacional de Controle a Tuberculose

PSF: Programa Saúde da Família

SUS: Sistema Único de Saúde

TB: Tuberculose

TBMDR: Tuberculose Multidroga Resistente

UBS: Unidade Básica de Saúde 


\section{INTRODUÇÃO}

A igualdade é o princípio pelo qual todo o cidadão pode invocar os mesmos direitos. A aplicação literal desse princípio constitucional no campo da saúde implica no acesso universal e igualitário às ações e serviços, na proibição de preconceitos ou privilégios ${ }^{1}$ e na gratuidade do atendimento ${ }^{2}$ (VIANNA et al, 2001).

O conceito de equidade em saúde, no entanto, propõe igualdade de acesso segundo as necessidades de cada um com o intuito de garantir direitos diferenciados aos mais carentes (Vianna et al, 2001).

Na década de 80 a Organização Mundial da Saúde (OMS) formulou a estratégia -"Saúde Para Todos no Ano 2000" com o intuito de promover ações baseadas na noção de necessidade, direcionada a atingir a todos independentemente das diferenças culturais, étnicas e socioeconômicas (WHO, 1985). Desse modo a principal questão a ser tratada pelas políticas que almejam equidade em saúde é a redução ou eliminação das diferenças criando igual oportunidade a todos (VIANNA et al, 2003).

No Brasil, em meados dos anos 80, o sistema de saúde passou por uma reforma visando garantir o direito à saúde e a distribuição equitativa dos recursos disponíveis neste setor. Assim a equidade nos serviços de saúde implicaria na equidade horizontal (não existência de diferenças onde as necessidades são iguais) e equidade vertical (distribuição dos serviços de saúde segundo as necessidades de cada local) (VIANA et al, 2003). No SUS (Sistema Único de Saúde) a universalidade do acesso é garantida através da gratuidade na utilização dos serviços. Porém os custos indiretos desses serviços incluem transportes, espera para o atendimento, aquisição de medicamentos dentre outros, os quais tendem a ser maiores para os grupos de menor renda, pois com maior freqüência esse grupo reside em áreas onde a oferta de serviços é menor dificultando o acesso (TRAVASSOS, 1997).

\footnotetext{
${ }^{1}$ Lei $8080 / 90$, art. $7^{\circ}$, IV

${ }^{2}$ Lei 8080/90, art.43
} 
Portando, reduzir as desigualdades deve ser o objetivo principal de toda política pública e a busca dessa redução é fundamental para que ela seja considerada como social, pois nem toda ação do governo tem esse propósito mesmo quando desenvolvida em setores sociais como a saúde, educação, previdência e habitação (VIANNA et al, 2001).

\section{DIREITOS HUMANOS E IMIGRAÇÃO}

O regime internacional de direitos humanos atualmente reconhece 0 indivíduo como portador de direitos independentemente de sua nacionalidade, porém a implementação desses direitos permanece dependente dos Estados receptores de imigrantes. Em decorrência desse princípio, as políticas de migração devem ser basicamente direcionadas para os três tipos de migrações internacionais (reunificação familiar, refugiados e ilegais). As políticas de reunificação familiar fundamentam-se no direito de todo ser humano levar uma vida familiar normal; as políticas para os refugiados se baseiam no direito a fuga quando sua vida está sob ameaça e quanto aos ilegais, o Estado é incapaz de impor sanções eficientes a esse tipo de imigração (REIS, 2004).

Historicamente o Brasil foi constituído como país de imigração, sendo que a característica atual das migrações não está mais ligada à vinda de mão de obra para a agricultura e colonização, mas motivada pela busca de ascensão social (THÉRY, 2009). A entrada de estrangeiros no Brasil é controlada por três Ministérios (Justiça, Relações Exteriores, Trabalho e Emprego), entretanto a lei de estrangeiros, ainda vigente, fundamenta-se em pressupostos de segurança nacional do período do governo militar. Em vista disso, portarias do Conselho Nacional de Imigração (CNIg), ligado ao Ministério do Trabalho, atualizam a questão propondo a construção de políticas públicas voltadas a migração para o trabalho, visando a igualdade entre imigrantes legais e população local, o acesso à direitos básicos do cidadão como saúde e educação à imigrantes legais e ilegais e a integração 
do migrante na sociedade ${ }^{3}$, este conjunto de propostas são fundamentais para a construção de uma nova legislação imigratória baseada nos direitos humanos (ABEP, 2009).

Essa nova realidade imigratória brasileira levou a promulgação, em 2009, da Lei da Anistia Migratória que permite a regularização de estrangeiros ilegais no Brasil, permitindo a liberdade de circulação, o direito ao trabalho, o acesso à saúde, a educação pública e a justiça (THÉRY, 2009). Segundo o Ministério da Justiça, foram beneficiados aproximadamente 43 mil estrangeiros pela nova Lei de Anistia, dentre esses, com destaque para os bolivianos (17000, sendo 16,3 mil no estado de São Paulo), seguidos pelos chineses (5500), peruanos (4600), paraguaios (4100) e coreanos (1100), além de 2400 imigrantes de origem européia (MINISTÉRIO DA JUSTIÇA, 2010).

No município de São Paulo, a situação dos imigrantes bolivianos e a informalidade da indústria de confecção paulistana estão intimamente ligadas. Em vista disso, a Comissão Municipal de Direitos Humanos (CMDH) criou no início de 2009 o Comitê Paulista para Imigrantes Refugiados almejando a inserção e a promoção dos direitos humanos através da criação de um espaço de discussões e desenvolvimento de políticas direcionadas a comunidades imigrantes (PREFEITURA DE SÃO PAULO, 2010).

A situação atual a respeito de movimentos migratórios nacionais e internacionais revela a importância de análise mais abrangente dessa problemática; o que demanda a reformulação e ampliação de políticas e ações de acordo com essa nova situação de maneira a investigar as peculiaridades dos fluxos e dos grupos sociais envolvidos, defender os indivíduos de atravessadores e garantir os direitos humanos dos imigrantes e seus familiares (PATARRA, 2005).

\footnotetext{
${ }^{3}$ Proposta de Política Nacional de Imigração e Proteção ao Trabalhador Migrante. Disponível em: http://www.mte.gov.br/politicamigrante/default.asp
} 


\section{IMIGRAÇÃO E SAÚDE}

O principal objetivo dos sistemas de saúde é promover a saúde da população e ampliar sua expectativa de vida de acordo com os valores predominantes em cada sociedade (VARGAS et al, 2002).

A migração por si só não constitui fator de risco para a saúde, o seu efeito no imigrante, assim como nos padrões de morbidade e mortalidade depende de quem está migrando, quando migra, de onde emigra, para onde migra e dos parâmetros de saúde a serem avaliados (CARBALLO, 2007). Quando os imigrantes chegam ao seu destino se defrontam com outra realidade, como diferenças culturais, lingüísticas e administrativas, essa situação os torna mais vulneráveis a problemas de ordem física, psicológica e social podendo influenciar diretamente suas condições de saúde (CARBALLO E NERUKAR, 2001).

A saúde do imigrante está relacionada a diversos fatores como nível socioeconômico, estatutos vigentes no país receptor, além das vulnerabilidades que lhes são impostas pela própria condição de migrante, especialmente o estresse causado pelo isolamento social. Tais fatores são agravados pelas dificuldades com o idioma e de compreensão das leis do país, preconceitos, fragilidades com relação à ilegalidade, pela situação precária de emprego e habitação e pelas dificuldades de acesso aos serviços de proteção social. Todas essas características podem ser minimizadas se os países receptores criassem serviços complementares específicos a estas populações (WOLFFERS, 2003).

Para que haja saúde é fundamental garantir condições de vida e trabalho (WHO, 1986). Dessa forma as populações migrantes devem gozar dos mesmos direitos que a população nativa do país. Assim a sociedade deve ter como premissa prevenir a discriminação e a exclusão social, possibilitar o acesso à assistência à saúde, assegurando a promoção e proteção dos direitos humanos a todos (PARLAMENTO EUROPEU, 2006).

A agenda européia, aprovada em 2000, reconheceu a existência de barreiras que dificultam o acesso à assistência à saúde, principalmente de 
imigrantes e minorias étnicas (CONSELHO DA UNIÃO EUROPÉIA, 2004). Em decorrência disso, a União Européia passou a adotar medidas promotoras do acesso aos direitos sociais e de saúde enfatizando atividades que beneficiam a melhoria da comunicação entre os pacientes e os serviços (COUNCIL OF EUROPE, 2001).

Há estudos que mostram que os sistemas nacionais de saúde baseados no apoio a segurança social, tal como existem em Portugal, Reino Unido e Irlanda apresentam menor custo e permitem maior acesso (TAMSMA e BERMAN, 2004). Em sistemas de saúde organizados com base em seguros de saúde, como a Suíça e a Grécia, cerca de 70 a 80.000 imigrantes indocumentados não possuem seguro e, portanto, vivem privados da assistência à saúde (FONSECA et al, 2007).

Para o Brasil a questão dos imigrantes latino-americanos sem recursos não tem sido prioridade na formulação de políticas sociais e programas de inserção (SARRIERA et al, 2005). O país é considerado restritivo quanto a sua política de imigração, por vezes 0 imigrante por ser indocumentado não é aceito em algumas instituições de ensino e quando aceito o seu certificado não é válido. O Sistema Único de Saúde é uma exceção por garantir o atendimento a todos sem distinção (SARRIERA et al, 2005).

Em vista disso, é necessário maior conhecimento das comunidades imigrantes em todos os seus contextos inclusive o da saúde e seus determinantes, criando condições para a identificação de prioridades de intervenção e para a avaliação de necessidades específicas dessas comunidades (GROVE, 2006).

As correntes migratórias oriundas de países de baixa renda per capita, constituem, por vários fatores, importante desafio para a saúde pública do país receptor, dentre eles, o potencial de alterar o seu perfil epidemiológico (CARBALLO E NERUKAR, 2001). A atuação dos serviços de saúde é fundamental para manter o bom estado de saúde das populações e promover seu bem estar (REIJNEVELD, 1998). Os imigrantes são geralmente vulneráveis por fatores como: situação econômica, falta de 
conhecimento sobre seus direitos ao acesso à assistência à saúde, situação de ilegalidade, dificuldades com relação à residência (muitas vezes em regiões periféricas) e barreiras lingüísticas e culturais que dificultam a integração entre atendente e paciente (REIJNEVELD, 1998; STRONKS et al, 2001), dessa forma são necessárias políticas públicas específicas para o monitoramento e manutenção de sua saúde.

\section{A TUBERCULOSE EM IMIGRANTES}

Populações economicamente desfavorecidas, minorias étnicas, imigrantes, moradores de rua, usuários de substâncias químicas são os mais vulneráveis para contrair a TB. Por encontrarem, com maior freqüência, barreiras no acesso aos cuidados rotineiros de sua saúde e à aquisição de medicamentos, pela menor adesão às orientações médicas, inclusive à conduta terapêutica indicada, geralmente obtêm piores resultados no tratamento da TB se comparados com a população geral (FIGUEROAMUNOZ E RAMON-PARDO, 2008).

A associação entre a TB e a pobreza ocorre devido à aglomeração, habitações mal ventiladas, desnutrição, tabagismo, estresse e privação social, essas características constituem grande desafio para o controle da TB em comunidades isoladas de grandes cidades. Além disso, a percepção de saúde e doença em alguns grupos étnicos minoritários é distinta, o que provoca impacto negativo sobre a saúde e a busca ao atendimento médico (FIGUEROA-MUNOZ E RAMON-PARDO, 2008).

A globalização desempenha papel fundamental no deslocamento crescente de pessoas no mundo, a chegada de grande grupo de imigrantes pode afetar o controle de TB nos países receptores pelo aumento significativo das fontes de infecção. Más condições de vida e a superlotação em assentamentos de refugiados aumentam o risco de infecção pelo Micobacterium tuberculosis. Grande parte dos casos de TB em países industrializados é proveniente de grupos minoritários, dos quais se destacam imigrantes recém-chegados de países com alta endemicidade da doença e 
que na maioria dos casos se concentram em comunidades carentes de cidades ricas (FIGUEROA-MUNOZ E RAMON-PARDO, 2008).

Em países desenvolvidos da Europa como Reino Unido e Irlanda do Norte, imigrantes originários de países em desenvolvimento possuem maiores taxas de TB se comparados à população nativa, principalmente nos primeiros anos após a emigração. Observa-se também que o impacto da epidemia de AIDS é maior em grupos étnicos minoritários em grandes cidades industrializadas (FIGUEROA-MUNOZ E RAMON-PARDO, 2008).

A incidência da TB entre imigrantes originários de países de alta endemicidade permanece elevada pelo menos dez anos após a imigração para países com baixos índices da doença. Essa característica pode ser explicada pela reativação de infecções antigas e infecções decorrentes da transmissão ocorrida após a imigração. Políticas de controle deveriam investigar a causa da persistência de alta incidência de TB em imigrantes mesmo após longos períodos de permanência em países de menor incidência (VOS et al, 2004).

Na Noruega e grande parte da Europa o controle da TB é baseado na busca de casos e contatos e ocasionalmente pela quimioprofilaxia para indivíduos infectados (CLANCY, 1991). A triagem obrigatória para a TB na chegada de imigrantes provenientes de países de alta prevalência e que irão permanecer no país por mais de três meses (FARAH et al, 2005), inclui teste tuberculínico para todos os grupos etários e exames radiológicos para maiores acima de 15 anos (INSTITUTE OF PUBLIC HEALTH, 2002). Tal triagem tem por objetivo detectar e tratar precocemente casos de TB, além de promover medidas de prevenção da transmissão entre contatos. Em vista disso, é de fundamental importância a avaliação da incidência de TB entre imigrantes segundo o país de origem (FARAH et al, 2005).

Os serviços de saúde devem reconhecer a existência de maior risco de TB e priorizar medidas oportunas de prevenção e controle. A avaliação da situação da TB em grupos minoritários oferece informações que permitem a agilização e maior efetividade das intervenções de saúde pública voltadas ao controle da TB. Por sua vez, se houver o envolvimento da comunidade, 
as dificuldades relativas às resistências e desconfianças desses grupos seriam superadas mais facilmente, pois aumenta o conhecimento e a percepção a respeito da $T B$, tornando mais efetiva as intervenções contra a doença (FIGUEROA-MUNOZ E RAMON-PARDO, 2008).

Portanto, a participação de profissionais da rede de serviços básicos de saúde, professores, organizações do terceiro setor e da população, em programas visando ampliar o conhecimento sobre a TB é primordial. Ações desse tipo necessitam de materiais suplementares como materiais educativos e folhetos em idiomas distintos de acordo com as distinções culturais (FIGUEROA-MUNOZ E RAMON-PARDO, 2008).

\section{IMIGRAÇÃO BOLIVIANA EM SÃO PAULO}

No passado a cidade de São Paulo recebeu duas importantes correntes imigratórias, a européia na segunda metade do século XIX (DA SILVA, 2006) e a japonesa no início do século XX (WOORTMANN, 1995). Atualmente há o predomínio da imigração latino-americana, coreana e africana (DA SILVA, 2006), dentre esses, o maior fluxo imigratório para o município de São Paulo é formado por bolivianos (URB AL rede 10, 2007).

A vinda de bolivianos para o Brasil se intensificou na década de 80 , atraídos principalmente pelas promessas de bons salários e pela baixa exigência de experiência prévia nas indústrias de confecção (DA SILVA, 1997). A maioria desses imigrantes é recrutada nas cidades de Santa Cruz de La Sierra, La Paz e Cochabamba, regiões receptoras de emigrantes procedentes das regiões mais pobres da Bolívia (CACCIAMALI E AZEVEDO, 2006).

$\mathrm{Na}$ Bolívia os centros de recrutamento de migrantes são os estados de La Paz, Cochabamba e Santa Cruz de la Sierra. A partir dessas cidades ocorre a emigração para o Brasil (São Paulo) e Argentina (Buenos Aires). Em São Paulo a maioria dos imigrantes bolivianos é oriunda do Estado de La Paz, seguidos pelos de Cochabamba, Oruro, Santa Cruz, Tarija, Beni, etc (DA SILVA, 1997). De acordo com o censo populacional do Instituto 
Nacional de Estatísticas (INE) da Bolívia, realizado em 2001, aproximadamente dois terços da população do país é composta de indivíduos de origem indígena. Essa população é formada por 35 povos distintos, dentre esses se destacam as etnias quéchua e aymará, residentes em sua maioria na zona rural do altiplano andino (La Paz, Potosí, Oruro, Chuquisaca e Cochabamba), as outras etnias estão dispersas pelo país, destacam-se os grupos Guaranis e Mojeños, habitantes das terras baixas (Santa Cruz, Beni, Pando e Tarija).

A situação de pobreza local, cria condições favoráveis à disseminação da TB que é umas das endemias urbanas mais severas a incidir na população da Bolívia (DIRECCIÓN GENERAL DE INMIGRACIÓN Y COOPERACIÓN AL DESAROLLO, 2007).

No município de São Paulo, as condições de trabalho as quais os imigrantes estão expostos na indústria de confecções são degradantes, com carga horária abusiva em ambiente adverso, geralmente, porões com pouca luminosidade e ventilação (DA SILVA, 2006), aumentando o risco de doenças respiratórias (IANNI E QUITÉRIO, 2004).

Dessa forma, as condições de vida da maioria dos bolivianos residentes em São Paulo (regime de trabalho excessivo, má alimentação e condições inadequadas de habitação) constituem fator predisponente a vários agravos à saúde, entre eles a TB (CACCIAMALLI E DE AZEVEDO, 2006). Por outro lado, a falta de documentação, as dificuldades de se expressar na língua portuguesa e o preconceito ao qual são submetidos, constituem obstáculos à busca de assistência médica pelo migrante (IANNI E QUITÉRIO, 2004).

\section{TUBERCULOSE NA AMÉRICA LATINA}

A TB é uma das enfermidades infecto contagiosas com mais ampla distribuição no globo, constituindo umas das principais causas de morte em pacientes portadores de HIV, principalmente em países em desenvolvimento (DYE et al, 1999). Estimativas referentes ao ano de 2008 apontam que no 
mundo haja 8,8 milhões de novos casos, 1,3 milhões de mortes por tuberculose e uma proporção de 15\% de co-infectados TB/HIV (WHO, 2010).

Nas Américas, o Brasil e o Peru contribuem com $50 \%$ dos casos estimados; se somarmos Bolívia, Equador, Haiti, Honduras, Guiana, México, Nicarágua e República Dominicana, esse valor eleva-se para $75 \%$ dos casos estimados.

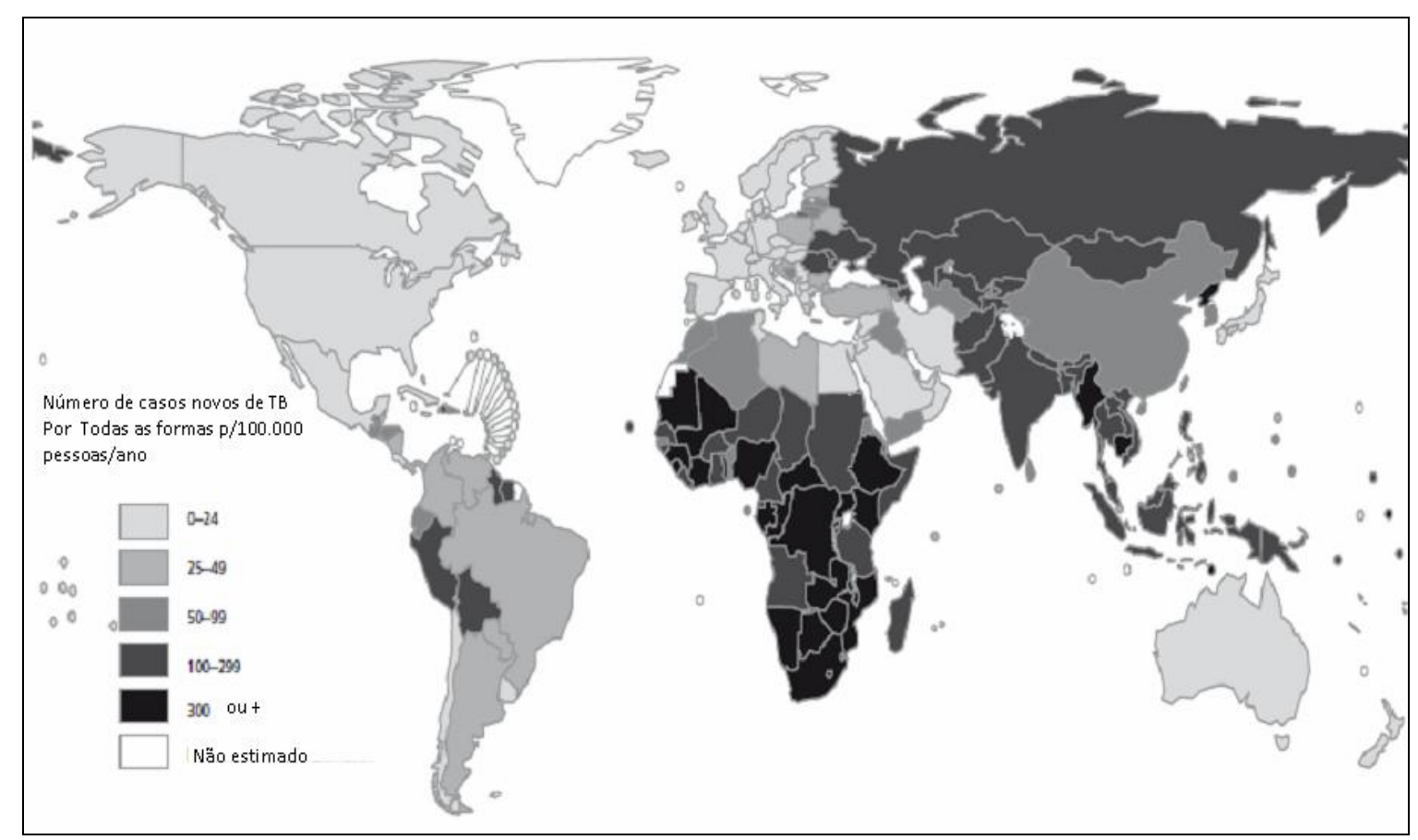

Fonte: WHO report 2009. Global tuberculosis control: epidemiology, strategy, financing; 2009.

\section{TUBERCULOSE NO BRASIL}

Em 2006 o Brasil ocupava o $14^{\circ}$ lugar entre os 23 países onde ocorrem $80 \%$ dos casos de tuberculose no mundo (WHO, 2006). Em 2009 o número de casos notificados situava-se em 77 mil, com uma taxa de incidência de 33,5/100.000 habitantes (MINISTÉRIO DA SAÚDE, 2009).

Estimativa efetuada pela OMS, em 2007, aponta 92102 casos de TB por todas as formas no Brasil, dos quais 80461 foram notificados, enquanto que a cobertura do DOTS (tratamento diretamente observado) teria atingido $75 \%$ (WHO, 2009). 
Em 2008, foram notificados no Brasil 85506 casos de TB por todas as formas, desse total, 70923 eram casos novos, 5024 recidivas e 4745 retratamentos pós-abandono, enquanto que, a proporção estimada de TBMDR situava-se em $0,2 \%$. Com relação aos desfechos, a taxa de cura foi de $59 \%$, a de abandono de tratamento atingiu $9,2 \%$, enquanto que $3 \%$ foram a óbito por TB, 3,6\% foram a óbito por outra causa. Do total de casos, $66 \%$ eram homens, com predomínio do grupo etário de 20 e 59 anos para os dois sexos, mas as taxas entre idosos são elevadas (MINISTÉRIO DA SAÚDE, 2008; CHAIMOWICZ, 2001).

Das metas internacionais adotadas pelo Brasil, de deteç̧ão de pelo menos $70 \%$ dos casos novos e de $85 \%$ de cura, somente a primeira é alcançada, havendo ainda dificuldades em atingir a meta de cura, em função das altas taxas de abandono que atingem cerca de 10 a 12\% (HIJJAR et al, 2005).

Em 1998, o Conselho Nacional de Saúde (CNS) definiu a tuberculose como um problema prioritário de saúde no país e estabeleceu diretrizes gerais de ação e metas para o Programa Nacional de Controle de Tuberculose (PNCT) (RUFFINO-NETTO, 1999).

No ano de 2004, os estados de São Paulo, Rio de Janeiro, Bahia, Minas Gerais, Rio Grande do Sul e Pernambuco foram os que mais notificaram casos de TB no país, cerca de $60 \%$. As taxas mais elevadas da doença se encontram em capitais e regiões metropolitanas (HIJJAR et al, 2005).

Segundo estimativas do Ministério da Saúde (MS) a TB é a principal causa associada ao óbito entre pacientes com AIDS, no Brasil temos anualmente 80000 casos novos de tuberculose e 32000 casos novos de AIDS, a prevalência de HIV em pacientes com TB é de $20 \%{ }^{4}$

A TB é a doença oportunista da AIDS mais freqüente no Brasil (WHO, 2004; RUFFINO-NETTO, 2002; CORBETT et al, 2003) e na vigência da TB

\footnotetext{
${ }^{4}$ MS/SVS/PN-DST/AIDS
} 
ativa verifica-se a diminuição da sobrevida de pacientes com AIDS (WHALEN et al, 2000).

O desenvolvimento da TB em paciente soropositivo para HIV depende do grau de imunossupressão, da categoria de exposição, dos hábitos de vida, do contato com indivíduos bacilíferos, do uso de profilaxia específica e da terapia anti-retroviral (KEIZER et al, 2000).

Após o início da utilização da terapia anti-retroviral altamente potente (HAART) houve uma significativa diminuição da incidência de TB entre pacientes infectados pelo HIV, especialmente em países como o Brasil onde os anti-retrovirais são de acesso gratuito (SANTORO-LOPES, 2002; COELHO et al, 2009; ANTUNES \& WALDMAN, 2001). Dessa maneira, o Brasil é uns dos poucos países com um alto número de co-infectados e uma política de acesso universal à terapia anti-retroviral o que o coloca em condições para estabelecer estratégias que minimizem a morbimortalidade da co-infecção TB/HIV. As medidas mais importantes para o controle da TB é o diagnóstico precoce, tratamento adequado e a busca de casos novos de indivíduos com TB (SILVEIRA, 2006).

\section{TUBERCULOSE NA BOLÍVIA}

A Bolívia é o terceiro país ocidental em incidência de TB, em 2007 a taxa de incidência sob todas as formas de TB foi de 155/ 100000 habitantes/ano e a taxa de mortalidade foi de 25/100 000 habitantes/ano (WHO, 2009), a porcentagem de casos de tuberculose multidroga resistente (TBMDR) foi de $1,2 \%$ para os casos incidentes e de $4,7 \%$ para os prevalentes. Nos indivíduos portadores de HIV a taxa de incidência e prevalência de TB foi de respectivamente 4,6/100.000 e 2,3/100.000 habitantes/ano e a de mortalidade foi 1,3/100.000 habitantes/ano (WHO. int, 2007). Em 2005, houve 6287 casos novos de TB pulmonar em toda a Bolívia, destacando-se os departamentos de Santa Cruz com 2242 casos e La Paz com 1354 casos. Da totalidade de casos pulmonares a taxa de cura 
foi de $78.5 \%$, a letalidade foi de $3.7 \%$ e a de abandono foi de $5,5 \%$ (PNCT BOLIVIA, 2005).

A TB é endêmica em todos os departamentos da Bolívia (USAID, 2007), com uma estimativa de 15000 casos novos por ano (MINISTÉRIO DE SALUD Y DEPORTES, 2002). A população mais afetada são indivíduos do sexo masculino (60\%), adolescentes e adultos jovens em idade reprodutiva e produtiva (53\%) (MINISTÉRIO DE SALUD Y DEPORTES, 2007).

$\mathrm{Na}$ América Latina e Caribe apenas quatro países possuem alta incidência de co-infecção TB/HIV (República Dominicana, Guiana, Haiti e Honduras) (PATZ, 2003). Em 2007, a proporção de co-infecção entre os casos de TB para República Dominicana foi de 31\%, para Guiana de 68\%, Haiti de $29 \%$ e Honduras de $42 \%$ (WHO. int, 2007).

A Bolívia possui uma das mais baixas taxas de prevalência de pessoas infectadas pelo HIV na América Latina e Caribe, cerca de 0,1\% em 2005. A epidemia é concentrada em homossexuais masculinos e jovens moradores de rua (USAID Bolívia, 2008).

Não se conhece a taxa atual da co-infecção de TB/HIV na Bolívia, porém se estima que, em 2000, essa taxa fosse menor de que 1/100.000 habitantes/ano e que proporção de casos de TB co-infetados pelo HIV situese abaixo de 1\%. No entanto, na capital La Paz essa proporção situa-se entre 10 e 19\% (CORBETT et al, 2003).

\section{TUBERCULOSE EM SÃO PAULO}

Em 2008 o total de casos novos no estado de São Paulo foi 16.044, com 1.295 recidivas e 1.136 retratamento após abandono, perfazendo um total de 18.476 casos. No município de São Paulo, nesse mesmo ano, a totalidade de casos de TB foi de 7.476, dos quais 6.383 casos novos, 512 $(8,0 \%)$ recidivas e $581(9,0 \%)$ retratamentos após abandono, dos quais obtiveram cura 5.091 (79,7\%), 1.151 (18,0\%) abandonos e 245 (3,8\%) óbitos 
por TB, do total de casos 14,5\% são co-infectados pelo HIV (MINISTÉRIO DA SAÚDE, 2008).

A incidência de TB da forma pulmonar é a mais comum, abrangendo $80 \%$ dos casos novos, sendo que entre pacientes co-infectados com HIV, essa proporção é de 75\%. Entre 1999 e 2000, 3,1\% dos casos de TB apresentaram MDR, na cidade de São Paulo (CVE, 2008).

Como assinalamos anteriormente, o MSP recebeu nos últimos anos expressivo número de migrantes oriundos de países com elevada incidência de TB, essas correntes migratórias oriundas de países de baixa renda per capita, constituem, por vários fatores, importante desafio para a saúde pública do país receptor, dentre eles, o potencial de alterar o seu perfil epidemiológico (CARBALLO E NERUKAR, 2001).

A atuação dos serviços de saúde é fundamental para manter o bom estado de saúde das populações e promover seu bem estar (REIJNEVELD, 1998). Os imigrantes são geralmente vulneráveis devido a diversos fatores como a situação econômica, a falta de conhecimento sobre seus direitos ao acesso à assistência à saúde, a situação de ilegalidade, às dificuldades com relação à residência (muitas vezes em regiões periféricas), e as barreiras lingüísticas e culturais que dificultam a integração entre atendente e paciente (REIJNEVELD, 1998; STRONKS et al, 2001), dessa forma são necessárias políticas públicas específicas para o monitoramento e manutenção de sua saúde.

O elevado número de imigrantes bolivianos em alguns distritos do município de São Paulo, a alta incidência de TB na Bolívia e a possível influência da migração no comportamento de TB nesse município (ANTUNES e WALDMAN, 2001; LINDOSO et al, 2008) tornam relevante o melhor conhecimento da TB nessa comunidade. A ausência de dados consistentes sobre a TB nessa comunidade, inclusive sobre aspectos importantes como o acesso aos serviços de saúde por esta população, justificam o interesse em se desenvolver um estudo sobre o assunto.

Esta pesquisa foi promovida com a finalidade de analisar 0 comportamento da TB na população de imigrantes bolivianos, investigar 
possíveis disparidades no desempenho do Programa de Controle da TB em relação à comunidade boliviana comparada com a população nacional, assim como, no acesso aos serviços de saúde e na qualidade do atendimento com vistas a melhor compreender as condições de saúde dessa comunidade. Como resultado, espera-se oferecer subsídios para a elaboração de políticas públicas com foco na promoção da saúde e da melhor integração dessa comunidade na sociedade brasileira. 


\section{OBJETIVOS}

- Descrever o comportamento da tuberculose entre imigrantes bolivianos residente nos distritos do Belém, Bom Retiro, Brás e Pari - município de São Paulo -, notificados entre 1998 e 2008, segundo características sóciodemográficas, história pregressa e atual da doença, aspectos relativos ao diagnóstico, tratamento e seus desfechos e a co-morbidades.

- Analisar o possível impacto dessa corrente migratória no comportamento da TB na área de interesse.

- Investigar possíveis disparidades no desempenho do Programa de Controle da Tuberculose entre membros da comunidade boliviana residentes nos distritos estudados comparada com a população nacional, assim como, diferenças no acesso dessa comunidade aos serviços de saúde e na qualidade do atendimento.

- Verificar a consistência dos resultados obtidos com fundamento na base de dados da vigilância da TB e obter informações complementares relativas às condições de vida e de acesso aos serviços e a percepção da qualidade desses serviços por parte de pacientes com TB, pertencentes a comunidade boliviana e tratados em Unidades Básicas de Saúde dos quatro distritos estudados. 


\section{MATERIAL E MÉTODOS}

\section{Delineamento e período de estudo}

Trata-se de estudo descritivo abrangendo o período de $1^{\circ}$ de janeiro de 1998 a 31 de dezembro de 2008, complementado por um inquérito efetuado entre 15/07/2009 a 05/10/2009.

\section{Área e população de estudo}

As áreas definidas para o estudo foram os distritos do Belém, Brás, Bom Retiro e Pari, localizados nas zonas leste (Belém) e Central (Brás, Bom Retiro e Pari) do município de São Paulo, regiões que abrigam grande quantidade de imigrantes bolivianos. Esses distritos apresentam O IDH variando entre 0,484 a 0,612, inferiores ao IDH do município de São Paulo que se situa em 0,841 (PMSP, 2000).

Hoje a expressiva presença boliviana é um fato inconteste na cidade de São Paulo, porém há controvérsias sobre sua magnitude. De acordo com a Pastoral dos Migrantes Latino-americanos, estima-se em 70 mil o número de imigrantes bolivianos indocumentados no município, 35 mil deles no bairro do Brás. O Consulado da Bolívia reconhece a existência de 50 mil imigrantes clandestinos e o Ministério Público, por sua vez, estima 200 mil imigrantes bolivianos entre os regulares e os irregulares em todo 0 município $^{5}$, o consenso entre essas estimativas é o fato de São Paulo abrigar o maior número de imigrantes bolivianos no Brasil (CYMBALISTA E XAVIER, 2007).

Os bolivianos vivem em bairros onde há maiores concentrações da indústria da confecção, como os da zona central da cidade (Bom Retiro, Brás, Pari e Barra Funda). Na zona leste da cidade (Belém, Tatuapé, Penha, Itaquera, Cangaíba, Engenheiro Goulart, Ermelino Matarazzo, Guaianases e

\footnotetext{
${ }^{5}$ Dados presentes no relatório final da Comissão Parlamentar de Inquérito para apurar a exploração do trabalho análogo ao de escravo da Câmara Municipal de São Paulo, publicado em fevereiro de 2006. Disponível em: http://www.camara.sp.gov.br/cpi_TrabalhoEscravo/001.htm [Acessado em 07/05/2010]
} 
São Mateus), zona norte (Vila Maria, Vila Guilherme, Casa Verde e Cachoeirinha) (DA SILVA, 2006).

A população de estudo abrangeu migrantes bolivianos portadores de TB, residentes nos distritos do Belém, Brás, Bom Retiro e Pari, de ambos os sexos, todas as idades cujos casos da doença foram notificados à vigilância da TB do município de São Paulo.

\section{Definições}

Definiu-se como caso de TB, indivíduos de ambos os sexos, de todas as idades, com residência atual nos distritos do Belém, Bom Retiro, Brás e Pari, que apresentaram quadro clínico compatível de TB e confirmação por meio de baciloscopia ou cultura de escarro com isolamento de $M$. tuberculosis e/ou RX com imagem sugestiva de tuberculose, ou ainda, pacientes com exames histopatológicos e/ou de cultura de $M$. tuberculosis positivos em material proveniente de localização extra pulmonar.

\section{Critérios de Inclusão e de Exclusão}

Foram incluídos no estudo, casos de TB notificados no período de $1^{\underline{0}}$ de janeiro de 1998 a 31 de dezembro de 2008, cuja residência fosse localizada nos distritos do Belém, Brás, Bom Retiro e Pari localizados no município de São Paulo.

Foram excluídos os pacientes que apresentaram mudança de diagnóstico, ou ainda aqueles para os quais não dispúnhamos de informações que permitissem confirmar o caso, nas fontes consultadas sobre essas características.

Para a análise comparativa relativa ao desempenho do programa de controle da TB entre bolivianos e não bolivianos tomou-se como grupo de comparação pacientes não bolivianos com TB, residentes nos distritos de interesse, cujos casos foram notificados a vigilância dessa doença no mesmo período. 


\section{Fonte de dados}

Os dados utilizados foram obtidos junto a Coordenação de Vigilância em Saúde (COVISA) da Secretaria Municipal de Saúde de São Paulo, com informações disponíveis pela vigilância da TB do município de São Paulo, na base de dados Epi TB (1998 a 2005) e TB Web (2006 a 2009); de questionário estruturado, aplicado pelo próprio pesquisador aos pacientes bolivianos em tratamento, em 2009; nas UBS Dr. Otávio A. Rodovalho, Marcus Wolosquer, Dr Manoel Saldiva Neto e Pari localizadas nos distritos estudados (Apêndice I) e livros de registros e fichas de notificação existentes nessas quatro UBS.

\section{Variáveis de estudo}

As variáveis de interesse para este estudo são as sócio-demográficas (sexo, idade, naturalidade, endereço, ocupação no início da doença, escolaridade, tempo de residência no Brasil e em São Paulo, freqüência com que visita a Bolívia, características da residência); as relativas ao contato com casos de TB (outros casos na família, contato no ambiente de trabalho), às condições de trabalho, a aspectos diagnósticos, clínicos e terapêuticos (intervalo entre início dos sintomas e diagnóstico e entre o diagnóstico e início do tratamento, esquema terapêutico, história prévia e atual da TB e desfechos de tratamento); co-morbidades (diabetes, câncer, HIV); comportamentais (tabagismo, alcoolismo); acesso aos serviços (tipo de transporte, tempo necessário para chegar à unidade de tratamento).

\section{Trabalho de Campo}

Com a finalidade de melhor conhecer as características da população estudada em relação a informações não disponíveis na base de dados da vigilância da TB, assim como, para verificar a consistência dos dados obtidos pela vigilância relativos ao acesso aos serviços de saúde efetuou-se 
um inquérito durante o período de 15/07/2009 a 05/10/2009. Com essa finalidade aplicou-se questionário estruturado (Apêndice I) entre pacientes de nacionalidade boliviana, em tratamento em Unidades Básicas de Saúde (UBS), localizadas nos distritos estudados. As UBS de estudo foram UBS Bom Retiro Dr. Otávio A. Rodovalho, UBS Belenzinho Marcus Wolosquer, UBS Brás Dr. Manoel Saldiva Neto e UBS Pari, únicas UBS dos distritos estudados.

\section{Preparação do Banco de Dados}

Os arquivos foram obtidos no formato Epi-Info e convertidos para 0 software SPSS versão 15 e após eliminação de duplicidades efetuou-se a análise de consistência. O critério utilizado para a identificação de pacientes bolivianos foi através de sobrenomes típicos de etnias indígenas bolivianas. Os nomes dos pacientes foram analisados individualmente com o intuito de identificar pacientes bolivianos, brasileiros e de outra nacionalidade. Tomamos como base a análise de sobrenomes de origem Quechua e Aymarás (etnias mais freqüentes na Bolívia) ${ }^{6}$.

\section{Análise dos Dados}

A base de dados obtida junto a COVISA referente ao período de 1998 a 2005 tem estrutura distinta daquela relativa ao período de 2006 a 2008, motivo pelo qual, parte das informações foi analisada separadamente para cada um desses períodos.

Os dados descritivos relativos à TB comparando o comportamento dessa doença entre brasileiros e bolivianos, nos distritos de interesse foi apresentado em tabelas e gráficos. As características dos pacientes foram comparadas de acordo com as variáveis de interesse. Nas análises comparativas entre as características analisadas de bolivianos e a de não bolivianos, utilizou-se para proporções os testes qui-quadrado de Pearson e

\footnotetext{
${ }^{6}$ Fonte: http://apellidosperuanos.wordpress.com/about/
} 
- Exato de Fisher e para variáveis contínuas o teste de Kruskal - Wallis. Toda análise foi efetuada usando os softwares estatísticos SPSS versão 15.

As taxas de incidência da população da área de estudo foram estimadas tomando-se os casos de TB como numerador e a população estimada dos distritos estudados para o meio do período ( $1^{0} \stackrel{0}{ }$ de julho) como denominador.

\section{Aspectos Éticos da Pesquisa}

Esta pesquisa observou as recomendações da Resolução nำ 196 de 10/10/96 - Conselho Nacional de Saúde para Pesquisa Científica em Seres Humanos. Foi submetido e aprovado pelo Comitê de Ética em Pesquisa da Faculdade de Saúde Pública da Universidade de São Paulo, sob o protocolo n. 1983 (Anexo II). As entrevistas somente foram efetuadas após o consentimento livre e esclarecido, que foi lido e assinado pelos indivíduos entrevistados (Apêndice II).

Os autores declaram que os pacientes não se envolveriam em situações de risco ao serem submetidos aos procedimentos usados neste estudo e que assumem o compromisso de garantir a privacidade das informações e o anonimato dos sujeitos, utilizando-se os dados assim obtidos exclusivamente para os propósitos desta pesquisa (Anexo I). 


\section{RESULTADOS}

No período de interesse foram notificados nos quatro distritos estudados 2434 casos de TB, sendo que 1644 (67,5\%), 740 (30,4\%) e 50 $(2,1 \%)$ deles eram, respectivamente de nacionalidade brasileira, boliviana e outras. Durante o período verificou-se aumento constante da participação proporcional de bolivianos em relação ao total de casos, variando de $15 \%$ em 1998 a 53\% em 2008. A distribuição ano a ano dos casos de TB nos distritos de interesse, segundo ano de diagnóstico e nacionalidade, são apresentados na Tabela 1.

Tabela 1: Casos notificados de TB por todas as formas e para todas as idades, segundo ano de diagnóstico e nacionalidade. Distritos do Belém, Bom Retiro, Brás e Pari. Município de São Paulo. 1998 a 2008.

\begin{tabular}{ccccc}
\hline & \multicolumn{3}{c}{ Nacionalidade } & Total \\
\cline { 2 - 4 } Ano & Brasileira & Boliviana & Outras & N $\%)$ \\
& $\mathbf{N}(\%)$ & $\mathbf{N}(\%)$ & $\mathbf{N}(\%)$ & $196(100,0)$ \\
\hline $\mathbf{1 9 9 8}$ & $161(82,1)$ & $30(15,3)$ & $5(2,6)$ & $240(100,0)$ \\
$\mathbf{1 9 9 9}$ & $192(80,0)$ & $43(17,9)$ & $5(2,1)$ & $209(100,0)$ \\
$\mathbf{2 0 0 0}$ & $159(76,1)$ & $47(22,5)$ & $3(1,4)$ & $226(100,0)$ \\
$\mathbf{2 0 0 1}$ & $170(75,2)$ & $49(21,7)$ & $7(3,1)$ & $266(100,0)$ \\
$\mathbf{2 0 0 2}$ & $189(71,1)$ & $70(26,3)$ & $7(2,6)$ & $246(100,0)$ \\
$\mathbf{2 0 0 3}$ & $183(74,4)$ & $57(23,2)$ & $6(2,4)$ & $224(100,0)$ \\
$\mathbf{2 0 0 4}$ & $145(64,7)$ & $79(35,3)$ & - & $202(100,0)$ \\
$\mathbf{2 0 0 5}$ & $120(59,4)$ & $77(38,1)$ & $5(2,5)$ & $232(100,0)$ \\
$\mathbf{2 0 0 6}$ & $129(55,6)$ & $100(43,1)$ & $3(1,3)$ & $193(100,0)$ \\
$\mathbf{2 0 0 7}$ & $105(54,4)$ & $83(43,0)$ & $5(2,6)$ & $200(100,0)$ \\
$\mathbf{2 0 0 8}$ & $91(45,5)$ & $105(52,5)$ & $4(2,0)$ & $2434(100,0)$ \\
\hline
\end{tabular}


As taxas de incidência de TB no município de São Paulo, em 2008, por distrito administrativo, com destaque para a área de estudo, e os Índices de Desenvolvimento Humano (IDH), por distritos do município de São Paulo, relativo ao ano 2000 (PMSP, 2000), é apresentada na Figura 1.

Figura 1: Mapa município de São Paulo. Distritos administrativos de estudo.

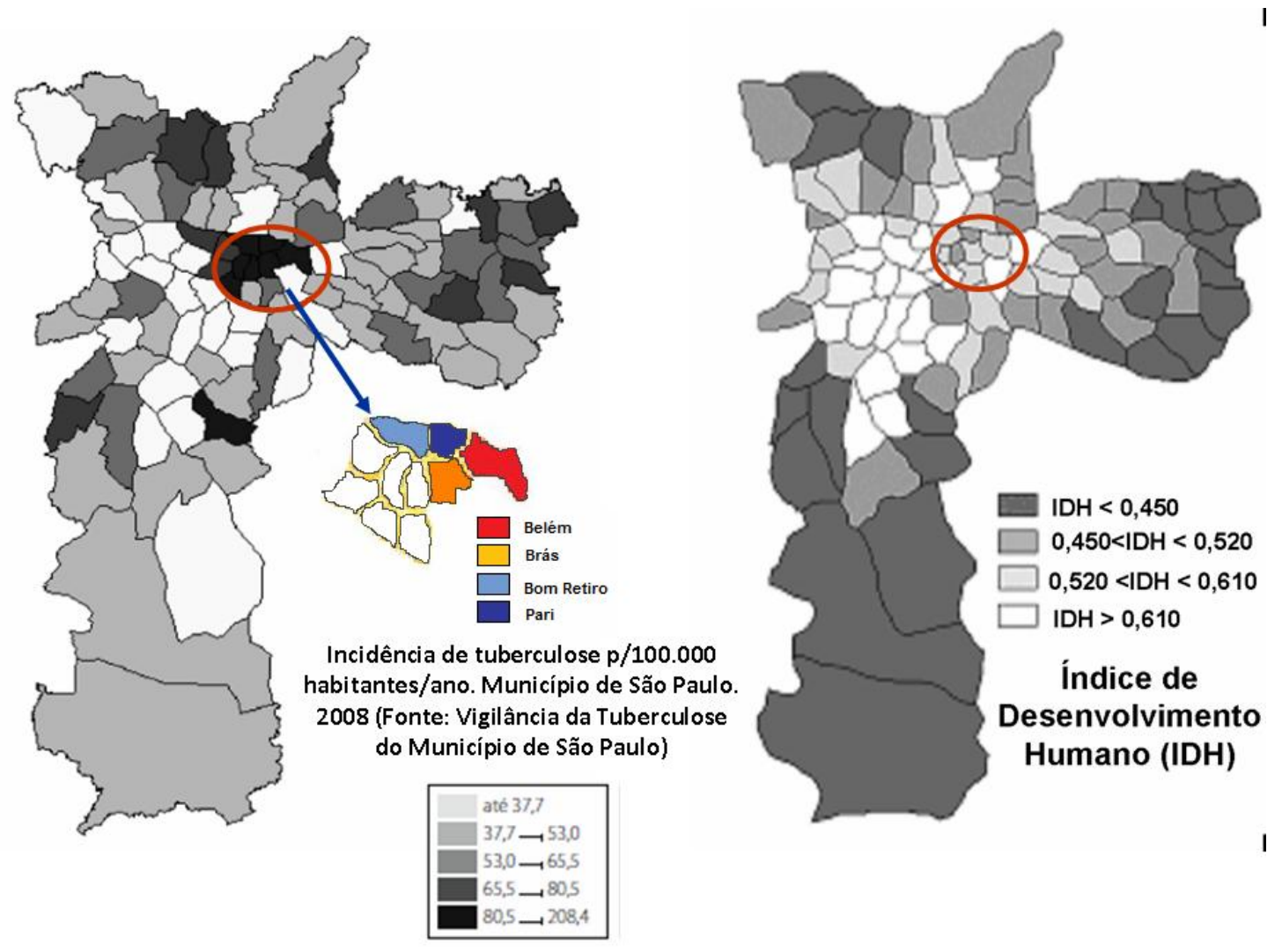

Figura 2: Taxa média de incidência de tuberculose por todas as formas e casos da doença, segundo a nacionalidade nos distritos do Belém, Bom Retiro, Barra Funda e Pari. Município de São Paulo. 1998 - 2008.

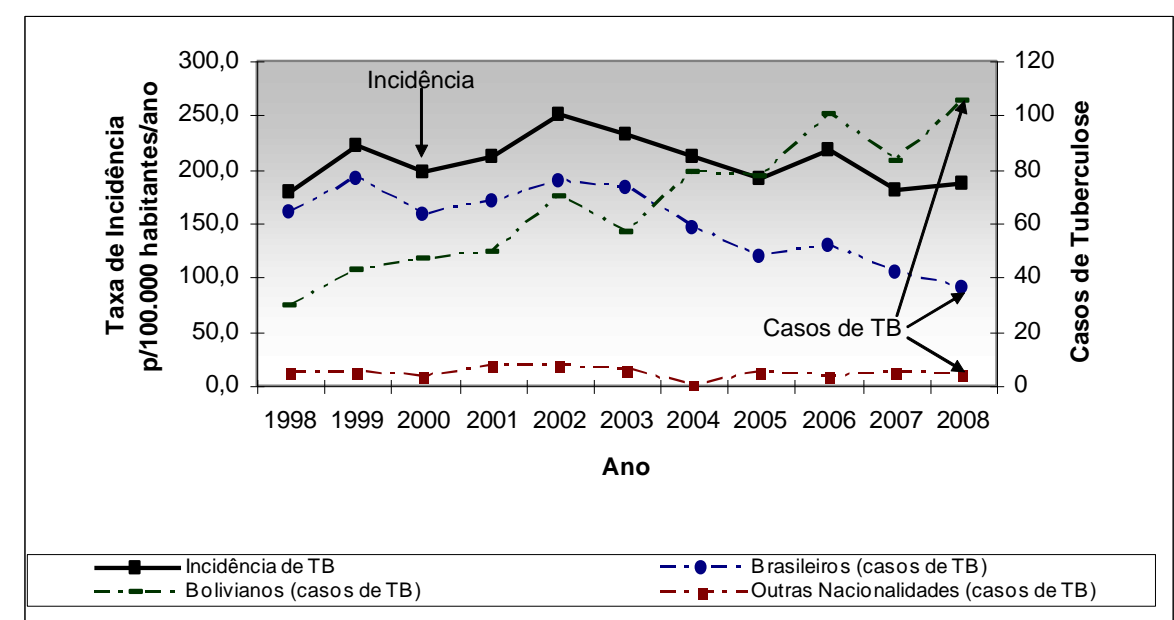

Fonte: Coordenadoria de Vigilância em Saúde (COVISA). Secretaria Municipal de Saúde São Paulo 
A taxa de incidência anual e o número de casos incidentes de TB por todas as formas e idade, segundo a nacionalidade, para o conjunto de distritos do Belém, Bom Retiro e Pari, entre 1998 e 2008, são apresentados na Figura 2 e Apêndice III. As taxas de incidência variaram de 179,3/100.000 habitantes/ano, em 1998, atingindo um pico em 2002 de 249,9/100.000 habitantes /ano, declinando em seguida, terminado o período com uma taxa de 186,8/100.000 habitantes /ano em 2008. O número de casos incidentes entre brasileiros diminuiu em $43,5 \%$ enquanto que entre bolivianos houve aumento de $250,0 \%$.

Como a base de dados disponível para o estudo referente ao período de 1998 a 2005 tem estrutura distinta daquela relativa ao período de 2006 a 2008, a partir deste ponto, parte dos resultados serão apresentados separadamente.

A taxa de incidência média anual de TB para todas as formas e todas as idades, no período de 2006 a 2008, para o município de São Paulo situou-se em 53/100.000 habitantes/ano, enquanto que, para os distritos do Pari foi de 157,5, Bom Retiro de 197,0, Brás de 212,8 e para o do Belém foi de 201,2/100.000/ano.

Analisando para cada um dos distritos de interesse, a proporção de casos notificados de TB entre bolivianos, verificamos que em todos houve aumento constante entre 2006 e 2008, sendo que no final do período, essa proporção atingia 60\% nos distritos do Pari e Belém. Em 2008, a exceção do Brás, nos demais distritos estudados observa-se que a proporção de casos notificados entre bolivianos foi a mais elevada (Tabela2). 
Tabela 2: Casos notificados de TB por todas as formas e para todas as idades, segundo ano do diagnóstico, distrito de residência e nacionalidade. Município de São Paulo. 2006 a 2008.

\begin{tabular}{lcccc}
\hline Características & \multicolumn{3}{c}{ Nacionalidade } & Total \\
\cline { 2 - 4 } & $\begin{array}{c}\text { Brasileira } \\
\mathbf{N}(\%) \\
(\mathbf{n = 3 2 5})\end{array}$ & $\begin{array}{c}\text { Boliviana } \\
\mathbf{N}(\%) \\
(\mathbf{n}=\mathbf{2 8 8})\end{array}$ & $\begin{array}{c}\text { Outras } \\
\mathbf{N}(\%) \\
(\mathbf{n}=\mathbf{1 2})\end{array}$ & $\begin{array}{c}\mathbf{N}(\%) \\
(\mathbf{n}=\mathbf{6 2 5})\end{array}$ \\
\hline & & & & \\
Distrito (ano) & & & & \\
Pari (2006) & $21(65,6)$ & $10(31,3)$ & $1(3,1)$ & $32(100,0)$ \\
Pari (2007) & $14(73,7)$ & $5(26,3)$ & - & $19(100,0)$ \\
Pari (2008) & $8(38,1)$ & $13(61,9)$ & - & $21(100,0)$ \\
& & & & \\
Bom Retiro (2006) & $38(62,3)$ & $22(36,1)$ & $1(1,6)$ & $61(100,0)$ \\
Bom Retiro (2007) & $25(50,0)$ & $22(44,0)$ & $3(6,0)$ & $50(100,0)$ \\
Bom Retiro (2008) & $22(43,1)$ & $27(52,9)$ & $2(3,9)$ & $51(100,0)$ \\
& & & & \\
Brás (2006) & $35(62,5)$ & $20(35,7)$ & $1(1,8)$ & $56(100,0)$ \\
Brás (2007) & $31(60,8)$ & $19(37,3)$ & $1(2,0)$ & $51(100,0)$ \\
Brás (2008) & $36(53,7)$ & $29(43,3)$ & $2(3,0)$ & $67(100,0)$ \\
& & & & \\
Belém (2006) & $35(42,2)$ & $48(57,8)$ & - & $83(100,0)$ \\
Belém (2007) & $35(47,9)$ & $37(50,7)$ & $1(1,4)$ & $73(100,0)$ \\
Belém (2008) & $25(41,0)$ & $36(59,0)$ & - & $61(100,0)$ \\
\hline
\end{tabular}

Para o período de 1998 a 2008, comparando brasileiros e bolivianos, segundo as características sócio-demográficas (Tabela 3), observamos que a média da idade para os primeiros foi de 39 anos versus 26 anos entre os brasileiros $(p<0,0001)$, havendo também entre os bolivianos, menor participação proporcional de homens, $71 \%$ versus $62 \%$ ( $p<0,0001)$. Observa-se menor proporção de desempregados entre bolivianos, $10,4 \%$ versus $2,4 \%$, sendo que a maioria deles trabalha na área de confecção, 2,8\% versus $69,3 \%$ $(p<0,0001)$. 
Tabela 3: Casos notificados de TB por todas as formas e idades, segundo características sócio-demográficas. Distritos do Belém, Bom Retiro, Brás e Pari. Município de São Paulo. 1998 a 2008.

\begin{tabular}{ccccc}
\hline Características & \multicolumn{2}{c}{ Nacionalidade } & & \\
\cline { 2 - 3 } & Brasileira & Boliviana & Total & Valor de $p$ \\
& $N(\%)$ & $N(\%)$ & $N(\%)$ & \\
& $\left(n=1644^{\star}\right)$ & $\left(n=740^{\star}\right)$ & $\left(n=2384^{\star}\right)$ & \\
\hline
\end{tabular}

Sexo

Feminino

Masculino

Faixa etária

$<5$ anos

5-14 anos

15-29 anos

30-40 anos

41-50 anos

51-60 anos

+60 anos

Média da idade (anos)
$475(28,9)$ $1169(71,1)$ $p<0,0001$

$280(37,8) \quad 755(31,7)$

$460(62,2) \quad 1629(68,3)$

\section{Escolaridade ${ }^{\star \star}$}

$$
\begin{aligned}
& <4 \text { anos } \\
& 4 \text { a } 8 \text { anos } \\
& >8 \text { anos }
\end{aligned}
$$

Profissão

Desempregado

Aposentado

Dona de casa

Detento

Confecção

Outros

$p<0,0001$

$\begin{array}{ccc}18(1,1) & 18(2,4) & 37(1,5) \\ 26(1,6) & 32(4,3) & 58(2,4) \\ 379(23,2) & 508(68,9) & 887(37,4) \\ 495(30,3) & 125(17,0) & 620(26,1) \\ 422(25,8) & 27(3,7) & 449(18,9) \\ 170(10,4) & 21(2,7) & 190(8,0) \\ 126(7,7) & 7(0,9) & 133(5,6)\end{array}$

26,1

$p<0,0001$

$p=0,443$

$\begin{array}{ccc}27(19,5 \%) & 28(19,8 \%) & 55(19,7 \%) \\ 56(40,6 \%) & 68(48,2 \%) & 124(44,4 \%) \\ 55(39,8 \%) & 45(31,9 \%) & 100(35,8 \%)\end{array}$

* A diferença entre o total de pacientes estudados e a soma de casos por categoria das variáveis corresponde a ausência de informação

** Dados referentes ao período de 2006 a 2008 
A história pregressa de TB para os períodos de 1998 a 2005 e de 2006 a 2008 estão apresentadas, respectivamente, nas Tabelas 4a e 4b.

Ao compararmos os períodos de 1998 a 2005 e de 2006 a 2008 (Tabelas 4a e 4b), observamos queda nas proporções de casos com histórico anterior de TB, de $23,3 \%$ para $16,9 \%$ entre brasileiros e de $16,9 \%$ para $6,9 \%$ entre bolivianos $(p<0,0001)$. Com relação ao tipo de início do tratamento anterior houve, do primeiro para o segundo período, aumento da proporção de casos novos de $48,3 \%$ para $84,9 \%$ entre brasileiros e de $64,5 \%$ para $85 \%$ entre bolivianos $(p<0,0001)$.

Quanto ao desfecho do tratamento da TB anterior, em ambos os grupos a taxa de cura foi maior no período de 1998 a 2005 se comparado com o período seguinte, sendo que tanto as taxas de cura como de abandono passam a ser semelhantes nos dois grupos, no segundo período. O tempo médio entre episódio anterior e atual é menor entre bolivianos em ambos os períodos, havendo diminuição desse intervalo do primeiro para o segundo período, assim como as diferenças entre brasileiros e bolivianos (Tabelas 4a e 4b). 
Tabela 4a: Casos notificados de TB por todas as formas e para todas as idades, segundo nacionalidade e a história pregressa da doença. Distritos do Belém, Bom Retiro, Brás e Pari. Município de São Paulo. 1998 a 2005.

\begin{tabular}{|c|c|c|c|c|}
\hline \multirow[b]{2}{*}{ Características } & \multicolumn{2}{|c|}{ Nacionalidade } & \multirow[b]{2}{*}{$\begin{array}{c}\text { Total } \\
N(\%) \\
\left(n=1771^{\star}\right)\end{array}$} & \multirow[b]{2}{*}{$\begin{array}{c}\text { Valor de } \\
\text { p }\end{array}$} \\
\hline & $\begin{array}{c}\text { Brasileira } \\
\quad N(\%) \\
\left(n=1319^{\star}\right)\end{array}$ & $\begin{array}{c}\text { Boliviana } \\
N(\%) \\
\left(n=452^{\star}\right)\end{array}$ & & \\
\hline TB no passado & $\mathrm{N}(\%)$ & $N(\%)$ & $N(\%)$ & $P=0,005$ \\
\hline Não & $955(76,7)$ & $360(83,1)$ & $1315(78,4)$ & \\
\hline Sim & $290(23,3)$ & $73(16,9)$ & $363(21,6)$ & \\
\hline $\begin{array}{l}\text { Forma clínica da TB anterior } \\
\text { Pulmonar }\end{array}$ & $65(77,4)$ & $26(86,7)$ & $91(79,8)$ & $p=0,395$ \\
\hline Ganglionar & $10(11,9)$ & $1(3,3)$ & $11(9,6)$ & \\
\hline Pleural & $2(2,4)$ & $2(6,7)$ & $4(3,5)$ & \\
\hline Disseminada & $2(2,4)$ & - & $2(1,8)$ & \\
\hline Outras & $5(6,0)$ & $1(3,3)$ & $6(5,3)$ & \\
\hline Tratamento da TB anterior ${ }^{\star *}$ & & & & $p=0,323$ \\
\hline Caso novo & $42(48,3)$ & $20(64,5)$ & $63(52,5)$ & \\
\hline Recidiva & $15(17,2)$ & $2(6,5)$ & $17(14,4)$ & \\
\hline Abandono & $29(33,3)$ & $9(29,0)$ & $38(32,2)$ & \\
\hline Falência & $1(1,1)$ & - & $1(0,8)$ & \\
\hline Desfecho da TB anterior & & & & $p=0,062$ \\
\hline Cura & $141(49,1)$ & $25(34,7)$ & $166(46,2)$ & \\
\hline Abandono & $144(50,2)$ & $47(65,3)$ & $191(53,2)$ & \\
\hline Falência & $2(0,7)$ & 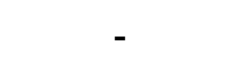 & $2(0,6)$ & \\
\hline $\begin{array}{l}\text { Tempo médio o entre } \\
\text { episódio anterior e o atual } \\
\text { (meses) }\end{array}$ & 86 & 50 & & $p<0,079$ \\
\hline
\end{tabular}


Tabela 4b: Casos notificados de TB por todas as formas e para todas as idades, segundo nacionalidade e história pregressa da doença. Distritos do Belém, Bom Retiro, Brás e Pari. Município de São Paulo. 2006 a 2008.

Características

Nacionalidade

\begin{tabular}{cccc}
\hline Brasileira & Boliviana & Total & Valor do $p$ \\
$N(\%)$ & $N(\%)$ & $N(\%)$ & \\
$\left(n=325^{\star}\right)$ & $\left(n=288^{\star}\right)$ & $\left(n=613^{\star}\right)$ &
\end{tabular}

TB no passado

$p<0,0001$

Não

$270(83,1) \quad 268(93,1) \quad 538(87,8)$

Sim

$55(16,9) \quad 20(6,9) \quad 75(12,2)$

Forma clínica da TB anterior

$p=0,956$

Pulmonar

$41(74,5) \quad 16(80,0) \quad 57(76,0)$

Ganglionar

$4(7,3)$

$1(5,0)$

$5(6,7)$

Pleural

$4(7,3)$

$1(5,0)$

$5(6,7)$

Disseminada

$1(1,8)$

$0(0,0)$

$1(1,3)$

Outras

$5(9,1) \quad 2(10,0)$

$7(9,3)$

Tratamento da TB anterior ${ }^{\star *}$ $p=0,627$

Caso novo

$47(85,5) \quad 17(85,0) \quad 64(85,3)$

Recidiva

$2(3,6)$

$0(0,0)$

$2(2,7)$

Abandono

$6(10,9)$

$3(15,0)$

$9(12,0)$

Desfecho da TB anterior

$p=0,949$

Cura

$16(30,8) \quad 6(30,0) \quad 22(30,6)$

Abandono

$36(69,2) \quad 14(70,0) \quad 50(69,4)$

Falência

Tempo médio o entre episódio

32,0

24,0

$p=0,103$

anterior $\mathbf{e} o$ atual (meses)

* A diferença entre o total de pacientes estudados e a soma de casos por categoria das variáveis corresponde a ausência de informação

** Situação no início do tratamento da TB anterior 
Para o histórico atual da doença, não se observa diferenças expressivas entre ambos os períodos (Tabelas $5 \mathrm{a}$ e $5 \mathrm{~b}$ ), predominando a forma pulmonar, cerca de $80,0 \%$. Verificou-se maior proporção de casos novos entre os bolivianos em ambos os períodos, sendo de $88,7 \%$ versus $78,5 \%$ entre 2006 e 2008 ( $\mathrm{p}<0,0001)$, as taxas de retratamento pós-abandono e por recidiva também foram menores entre os bolivianos em ambos os períodos, sendo que no segundo foram, respectivamente, de $5,9 \%$ versus $12,3 \%(p<0,001)$ e de $4,9 \%$ versus $9,2 \%(p<0,001)$ (tabela $5 a$ e $5 b)$. As mais elevadas taxas de cura e as menores taxas de abandono em ambos os períodos verificaram-se entre bolivianos, sendo que no segundo período foram de, respectivamente, 70,9\% versus $62,1 \%(p<0,001)$ e de $16,9 \%$ versus $22,4 \%(p<0,001)$. As taxas de óbitos por TB e por outras causas também foram menores entre bolivianos, respectivamente, de $1,6 \%$ versus $4,8 \%(p<0,001)$ e de $1,6 \%$ versus $10,3 \%$ $(p<0,001)$ (tabela $5 a$ e $5 b)$.

O número médio de contatos no domicílio cai de forma expressiva entre os brasileiros no segundo período, no entanto, não apresenta modificações expressivas entre bolivianos (tabela $5 a$ e $5 b$ ). 
Tabela 5a: Casos notificados de TB de todas as formas e para todas as idades, segundo a nacionalidade e história atual da doença. Distritos do Belém, Bom Retiro, Brás e Pari. Município de São Paulo. 1998 a 2005.

\begin{tabular}{|c|c|c|c|}
\hline \multirow[b]{2}{*}{ Características } & \multicolumn{2}{|c|}{ Nacionalidade } & \multirow[b]{2}{*}{$\begin{array}{c}\text { Total } \\
N(\%) \\
\left(n=1771^{\star}\right)\end{array}$} \\
\hline & $\begin{array}{c}\text { Brasileira } \\
N(\%) \\
\left(n=1319^{\star}\right)\end{array}$ & $\begin{array}{c}\text { Boliviana } \\
N(\%) \\
\left(n=452^{\star}\right)\end{array}$ & \\
\hline \multicolumn{4}{|l|}{ Forma clínica } \\
\hline Pulmonar & $1096(83,5)$ & $381(84,3)$ & $1477(83,7)$ \\
\hline Pleural & $67(5,1)$ & $31(6,9)$ & $98(5,6)$ \\
\hline Ganglionar & $62(4,7)$ & $15(3,3)$ & $77(4,4)$ \\
\hline Disseminada & $15(1,1)$ & $3(0,7)$ & $18(1,0)$ \\
\hline Outras & $72(5,5)$ & $22(4,9)$ & $94(5,3)$ \\
\hline
\end{tabular}

Caso Novo

Sim

$\begin{array}{ccc}1087(82,5) & 391(86,5) & 1478(83,5) \\ 136(10,3) & 44(9,7) & 180(10,2) \\ 89(6,8) & 16(3,5) & 105(5,9) \\ 6(0,5) & 1(0,2) & 7(0,4)\end{array}$

Desfecho do Tratamento

Cura

$\begin{array}{ccc}542(44,0) & 240(56,6) & 782(47,2) \\ 272(22,1) & 90(21,2) & 362(21,9) \\ 279(22,6) & 82(19,3) & 361(21,8) \\ 85(6,9) & 7(1,7) & 92(5,6) \\ 54(4,4) & 5(1,2) & 59(3,6)\end{array}$

Número médio de contatos

Número médio de contatos examinados

* A diferença entre o total de pacientes estudados e a soma de casos por categoria das variáveis corresponde a ausência de informação

** Transferências para Unidades de Saúde fora da região de estudo 
Tabela 5b: Casos notificados de TB de todas as formas e para todas as idades, segundo a nacionalidade e história atual da doença. Distritos do Belém, Bom Retiro, Brás e Pari. Município de São Paulo. 2006 a 2008.

\begin{tabular}{|c|c|c|c|c|}
\hline \multirow[b]{2}{*}{ Características } & \multicolumn{2}{|c|}{ Nacionalidade } & \multirow[b]{2}{*}{$\begin{array}{c}\text { Total } \\
\text { N (\%) } \\
\left(n=613^{\star}\right)\end{array}$} & \multirow[b]{2}{*}{$\begin{array}{c}\text { Valor de } \\
\qquad p\end{array}$} \\
\hline & $\begin{array}{c}\text { Brasileira } \\
N(\%) \\
\left(n=325^{\star}\right) \\
\end{array}$ & $\begin{array}{c}\text { Boliviana } \\
N(\%) \\
\left(n=288^{\star}\right) \\
\end{array}$ & & \\
\hline Forma clínica & & & & $p=0,093$ \\
\hline Pulmonar & $259(79,7)$ & $247(85,8)$ & $506(82,5)$ & \\
\hline Pleural & $26(8,0)$ & $14(4,9)$ & $40(6,5)$ & \\
\hline Ganglionar & $12(3,7)$ & $14(4,9)$ & $26(4,2)$ & \\
\hline Disseminada & $5(1,5)$ & $1(0,3)$ & $6(1,0)$ & \\
\hline Outras & $23(7,1)$ & $12(4,2)$ & $35(5,7)$ & \\
\hline Caso Novo & & & & $p<0,001$ \\
\hline Sim & $255(78,5)$ & $254(88,2)$ & $509(83,0)$ & \\
\hline Não - pós abandono & $40(12,3)$ & $17(5,9)$ & $57(9,3)$ & \\
\hline Não - recidiva & $30(9,2)$ & $14(4,9)$ & $44(7,2)$ & \\
\hline Falência & - & $3(1,0)$ & $3(0,5)$ & \\
\hline Desfecho do tratamento & & & & $p<0,001$ \\
\hline Cura & $180(62,1)$ & $180(70,9)$ & $360(66,2)$ & \\
\hline Abandono & $65(22,4)$ & $43(16,9)$ & $108(19,9)$ & \\
\hline Óbito outras causas & $30(10,3)$ & $4(1,6)$ & $34(6,3)$ & \\
\hline Transferência* * & $1(0,3)$ & $23(9,1)$ & $24(4,4)$ & \\
\hline Óbito TB & $14(4,8)$ & $4(1,6)$ & $18(3,3)$ & \\
\hline $\begin{array}{l}\text { Tempo médio de } \\
\text { tratamento (meses) }\end{array}$ & 5,6 & 5,6 & & $p<0,001$ \\
\hline $\begin{array}{l}\text { Número médio de } \\
\text { contatos }\end{array}$ & 1,6 & 4,3 & & $p<0,001$ \\
\hline $\begin{array}{l}\text { Número médio de } \\
\text { contatos examinados }\end{array}$ & 1,0 & 2,7 & & $p<0,001$ \\
\hline $\begin{array}{l}\text { * A diferença entre o total de paci } \\
\text { ausência de informacăo } \\
\text { }{ }^{* *} \text { Transferênncias para Unidades de }\end{array}$ & $\begin{array}{l}\text { tudados e a s } \\
\text { ra da região de }\end{array}$ & de casos por & ria das varíá & corresponde a \\
\hline
\end{tabular}


diagnóstico em ambulatórios públicos $(39,8 \%$ versus $32,6 \%)(p<0,001)$ entre os bolivianos (Tabela 6).

Tabela 6: Casos notificados de tuberculose por todas as formas e para todas as idades, segundo nacionalidade, esquema terapêutico e local de diagnóstico. Distritos do Belém, Bom Retiro, Brás e Pari. Município de São Paulo. 1998 a 2005.

\begin{tabular}{|c|c|c|c|c|}
\hline \multirow[b]{2}{*}{ Características } & \multicolumn{2}{|c|}{ Nacionalidade } & \multirow[b]{2}{*}{$\begin{array}{c}\text { Total } \\
\mathrm{N}(\%) \\
\left(\mathrm{N}=1771^{\star}\right)\end{array}$} & \multirow[b]{2}{*}{$\begin{array}{c}\text { Valor de } \\
\text { p }\end{array}$} \\
\hline & $\begin{array}{c}\text { Brasileira } \\
\text { N (\%) } \\
\left(n=1319^{\star}\right)\end{array}$ & $\begin{array}{c}\text { Boliviana } \\
N(\%) \\
\left(n=452^{\star}\right)\end{array}$ & & \\
\hline Tratamento & & & & $p=0,050$ \\
\hline Esquema I (RHZ) & $998(84,9)$ & $369(90,0)$ & $1367(86,2)$ & \\
\hline Esquema IR (RHZE) & $101(8,6)$ & $19(4,6)$ & $120(7,6)$ & \\
\hline Esquema III (SZEEt) & $7(0,6)$ & $2(0,5)$ & $9(0,6)$ & \\
\hline Outro & $69(5,9)$ & $20(4,9)$ & $89(5,6)$ & \\
\hline Local de diagnóstico & & & & $p<0,001$ \\
\hline PS hospital público & $462(38,9)$ & $133(32,3)$ & $595(37,2)$ & \\
\hline Ambulatório público & $387(32,6)$ & $164(39,8)$ & $551(34,5)$ & \\
\hline PS hospital universitário & $172(14,5)$ & $53(12,9)$ & $225(14,1)$ & \\
\hline Ambulatório privado & $37(3,1)$ & $14(3,4)$ & $51(3,2)$ & \\
\hline Ambulatório universitário & $45(3,8)$ & $5(1,2)$ & $50(3,1)$ & \\
\hline PS hospital privado & $44(3,7)$ & $6(1,5)$ & $50(3,1)$ & \\
\hline Outros & $40(3,4)$ & $37(9,0)$ & $77(4,8)$ & \\
\hline
\end{tabular}

* A diferença entre o total de pacientes estudados e a soma de casos por categoria das variáveis corresponde a ausência de informação PS: Pronto Socorro;

No período de 2006 a 2008, se comparado aos brasileiros, observa-se maior proporção de bolivianos que se trataram em UBS, com $72,6 \%$ versus $42,8 \%(p<0,001)$ e que receberam tratamento supervisionado $(81,9 \%$ versus $62,2 \%)(p<0,001)$. Nesse mesmo período a proporção de casos cujo intervalo de tempo entre início de sintomas e tratamento não apresenta diferença estatisticamente significativa entre brasileiros e bolivianos $(p>0,50)$ (Tabela 7$)$. 
Tabela 7: Casos de tuberculose por todas as formas e para todas as idades, segundo nacionalidade e aspectos relativos ao tratamento. Distritos do Belém, Bom Retiro, Brás e Pari. Município de São Paulo. 2006 a 2008.

\begin{tabular}{|c|c|c|c|c|}
\hline \multirow{2}{*}{ Características } & \multicolumn{2}{|c|}{ Nacionalidade } & \multirow[b]{2}{*}{$\begin{array}{c}\text { Total } \\
\text { N (\%) } \\
\left(n=613^{\star}\right)\end{array}$} & \multirow[b]{2}{*}{$\begin{array}{c}\text { Valor de } \\
\qquad p\end{array}$} \\
\hline & $\begin{array}{c}\text { Brasileira } \\
N(\%) \\
\left(n=325^{\star}\right)\end{array}$ & $\begin{array}{c}\text { Boliviana } \\
\text { N (\%) } \\
\left(n=288^{\star}\right)\end{array}$ & & \\
\hline Motivo da descoberta & & & & $p<0,001$ \\
\hline Demanda ambulatorial & $133(42,9)$ & $173(64,3)$ & $306(52,8)$ & \\
\hline Urgência/emergência & $104(33,5)$ & $56(20,8)$ & $160(27,6)$ & \\
\hline Elucidação em internação & $58(18,7)$ & $30(11,2)$ & $88(15,2)$ & \\
\hline Descoberta após óbito & $11(3,5)$ & $2(0,70)$ & $13(2,2)$ & \\
\hline Investigação de contato & $2(0,6)$ & $8(3,0)$ & $10(1,7)$ & \\
\hline Busca ativa instituição & $2(0,6)$ & - & $2(0,3)$ & \\
\hline Local de tratamento & & & & $p<0,001$ \\
\hline Unidade Básica de Saúde & $139(42,8)$ & $209(72,6)$ & $348(56,8)$ & \\
\hline Hospital & $103(31,7)$ & $27(9,4)$ & $130(21,2)$ & \\
\hline Instituto Clemente Ferreira & $38(11,7)$ & $40(13,9)$ & $78(12,7)$ & \\
\hline Instituto de infectologia & $18(5,5)$ & $3(1,0)$ & $21(3,4)$ & \\
\hline Outros & $14(4,3)$ & $9(3,1)$ & $23(3,8)$ & \\
\hline $\begin{array}{l}\text { Intervalo entre início dos } \\
\text { sintomas e do tratamento } \\
\text { (semanas) }\end{array}$ & & & & $p=0,661$ \\
\hline$<\mathrm{ou}=3$ & $66(42,9)$ & $78(47,0)$ & $144(45,0)$ & \\
\hline 4 a 8 & $57(37,0)$ & $51(30,7)$ & $108(33,8)$ & \\
\hline 9 a 12 & $16(10,4)$ & $21(12,7)$ & $37(11,6)$ & \\
\hline $13 e+$ & $15(9,7)$ & $16(9,6)$ & $31(9,7)$ & \\
\hline Tipo tratamento & & & & $p<0,001$ \\
\hline Supervisionado & $122(62,2)$ & $194(81,9)$ & $316(73,0)$ & \\
\hline Auto-administrado & $74(37,8)$ & $43(18,1)$ & $117(27,0)$ & \\
\hline
\end{tabular}

* A diferença entre o total de pacientes estudados e a soma de casos por categoria das variáveis corresponde a ausência de informação

Analisando os dados para todo o período de 1998 a 2008, observa-se que tanto para brasileiros quanto para imigrantes as proporções de casos 
diagnosticados foram de aproximadamente $55 \%$ por baciloscopia de escarro, $26 \%$ por cultura e de $19 \%$ por critério clínico-radiológico.

Tabela 8a: Casos notificados de TB por todas as formas e para todas as idades segundo nacionalidade e co-morbidades. Distritos do Belém, Bom Retiro, Brás e Pari. Município de São Paulo 1998 a 2005.

\begin{tabular}{|c|c|c|c|c|}
\hline \multirow[b]{2}{*}{ Características } & \multicolumn{2}{|c|}{ Nacionalidade } & \multirow[b]{2}{*}{$\begin{array}{c}\text { Total } \\
\text { N (\%) } \\
\left(\mathrm{n}=1771^{\star}\right)\end{array}$} & \multirow[b]{2}{*}{ Valor de } \\
\hline & $\begin{array}{c}\text { Brasileira } \\
N(\%) \\
\left(n=1319^{\star}\right)\end{array}$ & $\begin{array}{c}\text { Boliviana } \\
N(\%) \\
\left(n=452^{\star}\right)\end{array}$ & & \\
\hline Diabetes & & & & $p=0,003$ \\
\hline Não & $1120(94,8)$ & $370(98,4)$ & $1490(95,7)$ & \\
\hline Sim & $61(5,2)$ & $6(1,6)$ & $67(4,3)$ & \\
\hline Alcoolismo & & & & $p<0,000$ \\
\hline Não & $940(79,5)$ & $358(94,5)$ & $1298(83,2)$ & \\
\hline Sim & $242(20,5)$ & $21(5,5)$ & $263(16,8)$ & \\
\hline Doença mental & & & & $p=0,089$ \\
\hline Não & $1172(99,2)$ & $377(100,0)$ & $1549(99,4)$ & \\
\hline Sim & $9(0,8)$ & - & $9(0,6)$ & \\
\hline
\end{tabular}

* A diferença entre o total de pacientes estudados e a soma de casos por categoria das variáveis corresponde a ausência de informação

Nos dois períodos de estudo a proporção de brasileiros com comorbidades é maior do que a de bolivianos. A proporção de brasileiros com coinfecção TB/HIV se comparados aos bolivianos é de $46,1 \%$ versus $7,1 \%(p<$ 0,0001) no período de 1998 a 2005, porem com uma elevada proporção de pacientes sem informação quanto a essa situação (36\%) e de $20,3 \%$ versus 0,7\% ( $p<0,001)$ no período de 2006 a 2008 (Tabela 8b), desta vez, com uma proporção muito inferior de casos com informação ignorada (8,3\%). A prevalência de alcoolismo também se mostrou inferior entre bolivianos em ambos os períodos, sendo que a mesma foi de, respectivamente, 4,6\% versus $18,4 \%(p<0,0001)$ (Tabela $8 a)$ e de 2,4\% versus 15,1\% ( $p<0,0001)$ (Tabela 8b). Também com referência a diabetes verificamos resultado similar, A prevalência 
desta co-morbidade também se mostrou inferior entre bolivianos em ambos os períodos, sendo que a mesma foi no primeiro período de 1,6\% versus $5,2 \%$ $(p<0,0001)$ (Tabela 8a) e no segundo de $1,4 \%$ versus $4,3 \%(p<0,0001)$ (Tabela $8 b)$.

Tabela 8b: Casos notificados de TB por todas as formas e para todas as idades, segundo nacionalidade e co-morbidades. Distritos do Belém, Bom Retiro, Brás e Pari. Município de São Paulo. 2006 a 2008.

\begin{tabular}{|c|c|c|c|c|}
\hline \multirow[b]{2}{*}{ Características } & \multicolumn{2}{|c|}{ Nacionalidade } & \multirow[b]{2}{*}{$\begin{array}{c}\text { Total } \\
N(\%) \\
\left(n=613^{\star}\right)\end{array}$} & \multirow[b]{2}{*}{ Valor de $p$} \\
\hline & $\begin{array}{c}\text { Brasileira } \\
\begin{array}{c}N(\%) \\
\left(n=325^{\star}\right)\end{array}\end{array}$ & $\begin{array}{c}\text { Boliviana } \\
N(\%) \\
\left(n=288^{\star}\right)\end{array}$ & & \\
\hline HIV/AIDS & & & & $p<0,001$ \\
\hline Não & $259(79,7)$ & $286(99,3)$ & $545(88,9)$ & \\
\hline Sim & $66(20,3)$ & $2(0,7)$ & $68(11,1)$ & \\
\hline Diabetes & & & & $p=0,033$ \\
\hline Não & $311(95,7)$ & $284(98,6)$ & $595(97,1)$ & \\
\hline Sim & $14(4,3)$ & $4(1,4)$ & $18(2,9)$ & \\
\hline Alcoolismo & & & & $p<0,001$ \\
\hline Não & $276(84,9)$ & $281(97,6)$ & $557(90,9)$ & \\
\hline Sim & $49(15,1)$ & $7(2,4)$ & $56(9,1)$ & \\
\hline Doença mental & & & & $p=0,059$ \\
\hline Não & $321(98,8)$ & $288(100,0)$ & $609(99,3)$ & \\
\hline Sim & $4(1,2)$ & & $4(0,7)$ & \\
\hline
\end{tabular}

* A diferença entre o total de pacientes estudados e a soma de casos por categoria das variáveis corresponde a ausência de informação 
Tabela 9: Distribuição de casos de TB por todas as causas e para todas as idades, segundo nacionalidade e histórico de internações por TB. Distritos do Belém, Bom Retiro, Brás e Pari. Município de São Paulo. 1998 a 2005.

\begin{tabular}{ccccc}
\hline \multirow{3}{*}{ Características } & \multicolumn{3}{c}{ Nacionalidade } & \\
\cline { 2 - 3 } & Brasileira & Boliviana & Total & Valor de $p$ \\
& $N(\%)$ & $N(\%)$ & $N(\%)$ & \\
& $\left(n=1319^{*}\right)$ & $\left(n=452^{\star}\right)$ & $\left(n=1771^{\star}\right)$ & \\
\hline
\end{tabular}

Internação

Não

Sim

Média do Tempo de

internação (em dias)

Motivo internação

Elucidação diagnóstica

Insuficiência respiratória

Causas sociais

AIDS

Hemoptise

Caquexia

Não adesão tratamento

Meningite

Intolerância medicamentosa

Outros

Alta hospitalar

Tratamento ambulatorial

Óbito outra causa

Óbito TB

Transferência hospital

Cura

Óbito TB/AIDS

Pedida ou disciplinar

Evasão

Mudança de diagnóstico

$\begin{array}{lll}573(55,5) & 265(71,0) & 838(59,6) \\ 459(44,5) & 108(29,0) & 567(40,4)\end{array}$

$p<0,0001$

$34,8 \quad 16,7$

$p<0,0001$

$p=0,001$

$163(35,1) \quad 47(43,5) \quad 210(36,7)$

$87(18,8) \quad 14(13,0) \quad 101(17,7)$

$40(8,6) \quad 3(2,8) \quad 43(7,5)$

$39(8,4) \quad 2(1,9) \quad 41(7,2)$

$19(4,1) \quad 9(8,3) \quad 28(4,9)$

$22(4,7) \quad 2(1,9) \quad 24(4,2)$

$16(3,4) \quad 1(0,9) \quad 17(3,0)$

$12(2,6) \quad 4(3,7) \quad 16(2,8)$

$5(1,1) \quad 5(4,6) \quad 10(1,7)$

$61(13,1) \quad 21(19,4) \quad 82(14,2)$

$$
p=0,042
$$

$300(65,4) \quad 86(81,1) \quad 386(68,3)$

$56(12,2) \quad 6(5,7) \quad 62(11,0)$

$43(9,4) \quad 3(2,8) \quad 46(8,1)$

$28(6,1) \quad 8(7,5) \quad 36(6,4)$

$13(2,8) \quad 0(0,0) \quad 13(2,3)$

$6(1,3) \quad 2(1,9) \quad 8(1,4)$

$10(2,2) \quad-\quad 10(1,8)$

$2(0,4) \quad 1(0,9) \quad 3(0,5)$

$1(0,2) \quad 0(0,0) \quad 1(0,2)$

* A diferença entre o total de pacientes estudados e a soma de casos por categoria das variáveis corresponde a ausência de informação 
Analisando os dados para o período de 1998 a 2005, observa-se maior proporção de internação durante o tratamento da TB entre brasileiros $44,5 \%$ versus 29\% ( $p<0,0001)$, com tempo médio de internação maior entre brasileiros 35 dias versus 17 dias $(p=0,0001)$; maior proporção de internação para elucidação diagnóstica $43,5 \%$ versus $35,1 \%$ entre bolivianos enquanto que internação por co-morbidades e causas sociais predominou entre brasileiros $13 \%$ versus $6 \%$ e $9 \%$ versus $3 \% \quad(p<0,0001)$; a maior parte das altas hospitalares para tratamento ambulatorial foi entre bolivianos $81,1 \%$ versus $65,4 \%(p=0,023)$ (Tabela 9)

Entre os brasileiros $60,0 \%$ dos internados eram co-infectados HIV/TB, enquanto que para os bolivianos $10 \%$ dos pacientes internados eram coinfectados HIV/TB $(p<0,001)$. A proporção de pacientes internados com história pregressa de TB foi de $30 \%$ entre os brasileiros e de $19 \%$ entre os bolivianos.

\section{Caracterização dos pacientes bolivianos em tratamento em 2009}

Nas Unidades Básicas de estudo havia um total de 38 imigrantes bolivianos em tratamento, desse total 26 imigrantes aderiram à entrevista realizada entre 15/07/2009 e 05/10/2009, dos quais 11 se encontravam na UBS Marcus Wolosquer (Belém), 4 na Unidade Dr. Manoel Saldiva Neto (Brás) e 11 na UBS Pari, não houve adesão de respondentes na UBS Otávio A. Rodovalho (Bom Retiro), onde havia dois imigrantes bolivianos em tratamento.

Essa entrevista teve 0 intuito de coletar dados referentes a características específicas da comunidade boliviana com relação ao Programa de Controle de Tuberculose (PCT) sob sua ótica, acesso ao atendimento, características sócio-demográficas e alguns aspectos clínicos sobre a doença.

Sete meses após o período de entrevista houve o retorno às UBS de estudo com o intuito de colher informações, através de fichas de notificação e livro de acompanhamento, sobre esquema de tratamento e desfecho dos pacientes imigrantes que aderiram à entrevista.

Dos imigrantes entrevistados 19 (73\%) era proveniente do estado de La Paz e os municípios de origem mais freqüentes são Omasuyos (15\%) e Murillo (11,5\%). Desses imigrantes $85 \%$ pertenciam da etnia indígena Aymarás.

Sessenta e dois porcento dos pacientes entrevistados estão no Brasil há 
menos de três anos e $62 \%$ não visitaram o país de origem desde a chegada ao Brasil. Entre os 26 imigrantes em tratamento para TB não foi observado diferenças quanto ao sexo e a média de idade foi de 27 anos.

Figura 3: Mapa Bolívia. Estados da Bolívia com maior concentração de emigrantes para o Brasil.

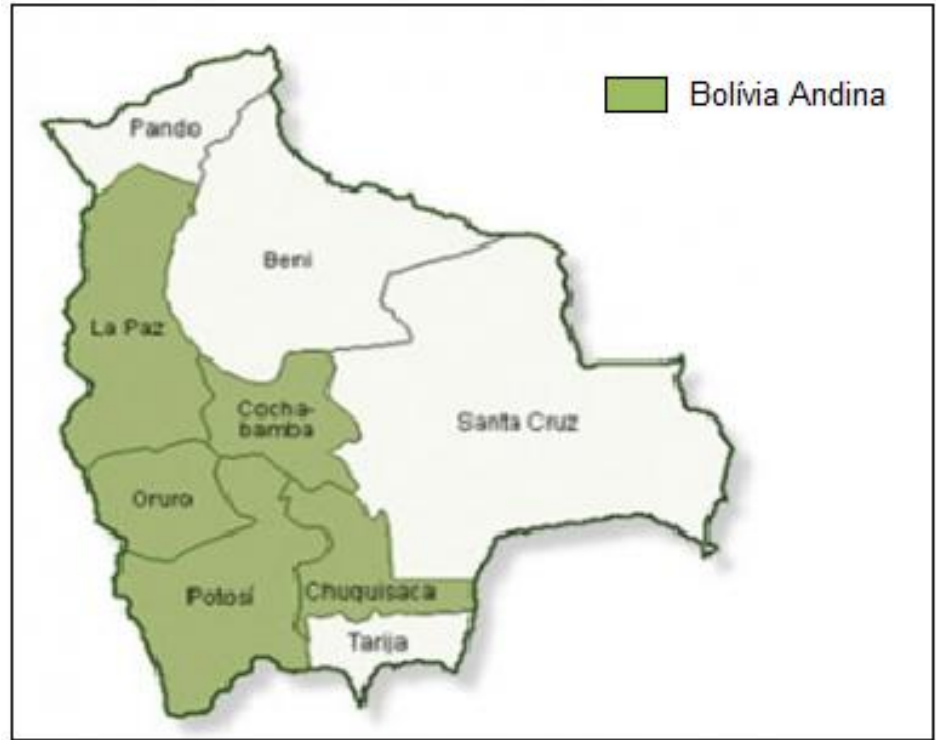

Dos pacientes entrevistados $50 \%$ são casados, $42 \%$ solteiros, há um único viúvo, no qual seu cônjuge foi a óbito em decorrência da TB. Em média, esse grupo tem dez anos de estudo formal; 88,5\% tinha a confecção como ocupação no início da doença, havendo um caso de desemprego (4\%); 91\% relatou trabalhar diariamente mais de 12 horas e a média salarial da amostra entrevistada foi de $\mathrm{R} \$ 445,00$.

Os locais de residência e as condições de moradia são apresentados na tabela 10. Entre os entrevistados 15 (58\%) foram vacinados com BCG na infância, 5 (19\%) tiveram histórico de TB anterior, dentre eles, 3 (11,5\%) obtiveram cura e $2(8 \%)$ abandonaram o tratamento. Com relação ao tempo decorrido entre o último episódio e o atual 4 deles (15,4\%) foram acometidos pela TB há menos de cinco anos e 1 (4\%) teve a enfermidade há cinco anos (Tabela 11).

Vinte e dois pacientes (84,6\%) apresentavam TB pulmonar no evento correspondente à entrevista, cinco deles (19,2\%) haviam sido internados em decorrência desse episódio e o período entre o início dos sintomas e o diagnóstico foi para 17 deles $(65,5 \%)$, de 3 a 6 semanas e para 12 pacientes 
$(46,2 \%)$ o início do tratamento ocorreu menos de uma semana depois do diagnóstico. Em 23 (88,5\%) pacientes o adoecimento e diagnóstico ocorreram no Brasil, o diagnóstico foi efetuado em UBS e hospitais em 50\% (13) e 38,5\% (10) deles, respectivamente (Tabela 11).

Tabela 10: Casos de tuberculose em imigrantes bolivianos* em tratamento em Unidades Básicas de Saúde, segundo características da residência. Distritos do Belém, Bom Retiro, Brás e Pari. Município de São Paulo, 2009.

\begin{tabular}{|c|c|c|}
\hline \multirow[b]{2}{*}{ Características } & \multicolumn{2}{|c|}{$(n=26)$} \\
\hline & $\mathrm{N}$ & $\%$ \\
\hline \multicolumn{3}{|c|}{ Distrito de residência** } \\
\hline Bom Retiro & 1 & 3,8 \\
\hline Brás & 7 & 26,9 \\
\hline Pari & 8 & 30,8 \\
\hline Belém & 8 & 30,8 \\
\hline \multicolumn{3}{|l|}{ Tipo residência } \\
\hline Apartamento & 4 & 15,4 \\
\hline Casa alvenaria & 1 & 3,8 \\
\hline Local de trabalho & 21 & 80,8 \\
\hline \multicolumn{3}{|c|}{ Número de cômodos } \\
\hline Dois & 1 & 3,8 \\
\hline Três & 9 & 34,6 \\
\hline Quatro & 5 & 19,2 \\
\hline Cinco & 6 & 23,1 \\
\hline+ de cinco & 5 & 19,2 \\
\hline \multicolumn{3}{|c|}{ Pessoas por cômodo } \\
\hline Uma & 1 & 3,8 \\
\hline Duas & 16 & 61,5 \\
\hline Três & 5 & 19,2 \\
\hline Quatro & 3 & 11,5 \\
\hline+ de cinco & 1 & 3,8 \\
\hline \multicolumn{3}{|c|}{ Pessoas p/ residência } \\
\hline Média & 9,2 & \\
\hline \multicolumn{3}{|l|}{ Condição ocupação } \\
\hline Alugada & 20 & 76,9 \\
\hline Cedida & 6 & 23,1 \\
\hline
\end{tabular}

* Pacientes que responderam ao questionário do inquérito efetuado em 2009

** Dois indivíduos não souberam informar endereço de residência 
Tabela 11: Casos de tuberculose em imigrantes bolivianos* em tratamento em Unidades Básicas de Saúde, segundo histórico da TB atual. Distritos do Belém, Bom Retiro, Brás e Pari. Município de São Paulo, 2009.

\section{Características}

$$
(n=26)
$$

$\mathrm{N}$

$\%$

Forma clínica

Pulmonar

Pleural

Ganglionar

1

Intestinal

Internação

Não

Sim

Início dos sintomas e diagnóstico (semanas) $^{\star \star}$

$<3$

3 a 6

12 a 14

15 ou +
2

17

1

1
7,7

65,4

3,8

3,8

Diagnóstico até início do tratamento (semanas) $^{\star * \star}$
$<1$
12
46,2
1
2 a 3
3
11,5
5
19,2
4
3
11,5
+ de 4
2
7,7

\section{Local do diagnóstico}

Brasil

Bolívia

\section{Local do início dos sintomas}

Brasil

Bolívia

Serviço aonde foi feito o diagnóstico

Hospital

Ambulatório

\footnotetext{
* Pacientes que responderam ao questionário do inquérito efetuado em 2009

** Intervalo entre o início dos sintomas e diagnóstico

*** Intervalo entre o diagnóstico e o início do tratamento
} 
Com referência aos sintomas apresentados no início do evento atual de TB, 18 (69,2\%) deles refere febre, 20 (66,9\%) tosse com escarro e $23(88,5 \%)$ perda de peso, a hemoptise esteve presente em 12 (46,2\%) dos pacientes (Tabela 12).

Tabela 12: Casos de tuberculose em imigrantes bolivianos* em tratamento nas Unidades Básicas de Saúde, segundo sintomas referidos. Distritos do Belém, Bom Retiro, Brás e Pari. Município de São Paulo, 2009.

\begin{tabular}{|c|c|c|}
\hline \multirow{2}{*}{ Sintomas } & \multicolumn{2}{|c|}{$(n=26)$} \\
\hline & $\mathrm{N}$ & $\%$ \\
\hline \multicolumn{3}{|l|}{ Febre } \\
\hline Não & 8 & 30,8 \\
\hline Sim & 18 & 69,2 \\
\hline \multicolumn{3}{|c|}{ Tosse com escarro } \\
\hline Não & 6 & 23,1 \\
\hline Sim & 20 & 66,9 \\
\hline \multicolumn{3}{|l|}{ Hemoptise } \\
\hline Não & 14 & 53,8 \\
\hline Sim & 12 & 46,2 \\
\hline \multicolumn{3}{|c|}{ Perda de peso } \\
\hline Não & 3 & 11,5 \\
\hline Sim & 23 & 88,5 \\
\hline
\end{tabular}

Em 12 (46,2\%) dos entrevistados houve outro caso de TB na família antes dos pacientes apresentarem os sintomas, porém $2(7,7 \%)$ de colegas de trabalho dos pacientes apresentavam TB antes do início dos sintomas do paciente. E após o início da doença $2(7,7 \%)$ relataram o diagnóstico de TB em algum familiar ou colega de trabalho (Tabela 13).

No grupo estudado não há presença das co-morbidades, como câncer e doença pulmonar obstrutiva crônica (DPOC), todos negaram ser fumantes, dois $(7,7 \%)$ declaram tabagismo no passado. Em relação ao consumo de álcool $12(46 \%)$ relataram nunca ter ingerido, enquanto que 11 (42\%) referem ingerir álcool apenas nos fins de semana. Um (4\%) paciente relatou ter vivido em regime prisional no passado (Tabela 14). 
Tabela 13: Casos de tuberculose em imigrantes bolivianos* em tratamento nas Unidades Básicas de Saúde, segundo o tipo de contatos. Distritos do Belém, Bom Retiro, Brás e Pari. Município de São Paulo, 2009.

\begin{tabular}{lcc}
\hline Contatos & $\mathrm{N}$ & $\%$ \\
\hline TB na família antes do diagnóstico & 14 & 53,8 \\
Não & 12 & 46,2 \\
Sim & & \\
TB entre colegas de serviço antes do diagnóstico & 24 & 92,3 \\
Não & 2 & 7,7 \\
Sim & & \\
TB na família após o diagnóstico & 24 & 92,3 \\
Não & 2 & 7,7 \\
Sim & &
\end{tabular}

Tabela 14: Casos de tuberculose em imigrantes bolivianos* em tratamento nas Unidades Básicas de Saúde, segundo co-morbidades e história de prisão no passado. Distritos do Belém, Bom Retiro, Brás e Pari. Município de São Paulo, 2009.

\begin{tabular}{lcc}
\hline Co-morbidades & \multicolumn{2}{c}{$(\mathrm{n}=26)$} \\
& $\mathrm{N}$ & $\%$ \\
\hline Câncer & 25 & 96,2 \\
$\quad$ Não & 0 & 0,0 \\
Sim & & \\
DPoC & 26 & 100,0 \\
Não & 0 & 0,0 \\
Sim & & \\
Tabagismo & & \\
$\quad$ Não & 24 & 92,3 \\
No passado & 2 & 7,7 \\
Sim & 0 & 0,0 \\
$\quad$ & & \\
Ingestão álcool & & \\
Nunca & 12 & 46,2 \\
Finais de semana & 11 & 42,3 \\
No passado & 3 & 11,5 \\
$\quad$ Prisão no passado & & \\
Não & & \\
Sim & 25 & 96,2 \\
& 1 & 3,8 \\
\hline
\end{tabular}


Quanto ao atendimento relacionado ao PCT, observamos que 16 $(61,5 \%)$ dos pacientes receberam visita domiciliar da equipe de saúde após diagnóstico de TB e todos relataram consulta mensal com o médico da Unidade.

Para 12 (46\%) dos pacientes a medicação era ministrada de forma supervisionada na UBS cinco vezes na semana, sete deles (27\%) são medicados na unidade uma vez por semana, levando consigo os medicamentos referentes aos outros dias da semana. A opinião dos imigrantes bolivianos em relação à qualidade de atendimento em relação ao tratamento supervisionado é satisfatória, 19 deles (73\%) relatam o atendimento atencioso, enquanto que apenas um caso (4\%) referiu o atendimento como pouco atencioso. Cinco dos entrevistados (19\%) relataram falta de medicação e o tempo de espera para a tomada dos medicamentos é no geral inferior a 15 minutos.

Quando se trata de controle de saúde preventivo 12 (73\%) dos imigrantes bolivianos em tratamento procuram as UBS e quando necessitam de exames mais específicos 13 deles (50\%) procuram UBS e nove (33\%) procuram hospitais.

Para aspectos relacionados ao acesso à saúde sete deles (27\%) não sabem ou acreditam que não tenham direito ao atendimento médico público no Brasil; 24 (92\%) deles vai a UBS a pé e os que se utilizam transporte público pagam com recursos próprios. Para chegar a UBS 19 deles (73\%) levam até 15 minutos e sete (27\%) entre 15 e 30 minutos. Quando o paciente chegou à Unidade de Atendimento com sintomas da TB, 23 (88,5\%) deles foram atendidos no mesmo dia.

Doze dos entrevistados (46\%) relataram que os profissionais de saúde e os médicos não os compreende bem e 11 (42\%) não compreendem as orientações dadas pelos profissionais da saúde e médicos.

O esquema I foi o mais utilizado (73\%). Dos 26 respondentes ao questionário $19(73 \%)$ se curaram $3(12 \%)$ foram transferidos para outras unidades e um caso (4\%) continuava em tratamento após seis meses do início do esquema, para os três restantes não foi possível obter essas informações. A média de tempo de tratamento entre os pacientes foi de 6 meses. 


\section{DISCUSSÃO}

No Brasil estima-se que existam cerca de um milhão de estrangeiros, dados provavelmente subestimados em face da dificuldade de quantificação de estrangeiros irregulares no país. As migrações internacionais mais recentes, décadas de 1990 e 2000, apresentam características distintas das anteriores, tanto por diferirem quanto aos países de origem, como por não terem vínculos com a economia rural. Entre as correntes migratórias recentes se destacam os, imigrantes latino-americanos, asiáticos e africanos (PATARRA e BAENINGER, 2006) e a maior concentração deles encontra-se no município de São Paulo (PATARRA e BAENINGER, 2004).

Nesse contexto há necessidade de promoção de políticas públicas em setores sociais ligadas à saúde que adequem-se a esse novo quadro (PATARRA e BAENINGER, 2006). Desse modo é indispensável o desenvolvimento de ferramentas legais, administrativas e de informação sobre migração com o objetivo de identificar as necessidades e urgências dos imigrantes a respeito de seus direitos sociais, culturais, econômicos e políticos (MÁRMORA, 1997).

Este trabalho apesar de focalizar somente quatro distritos do município de São Paulo, conseguiu levantar, sistematizar e analisar informações ainda não disponíveis aos gestores de saúde. Seus resultados certamente poderão servir de subsídios para a elaboração de estratégias específicas de intervenção para o controle da TB em comunidades de migrantes recém chegados de áreas de elevada endemicidade dessa doença, poderão também contribuir para a elaboração de políticas públicas voltadas a integração dessas comunidades e à promoção da equidade, especialmente, no setor da saúde.

Os distritos estudados são formados por bairros antigos do município de São Paulo, alguns deles historicamente vinculados às diferentes correntes migratórias que aqui chegaram desde o final do século XIX (PONCIANO, 2001). Situam-se nas áreas centrais do município e estão entre os seus distritos menos populosos, variando de oito a 20 mil habitantes. Neles se concentram, atualmente, importantes parcelas de migrantes recém chegados, com predomínio dos bolivianos (DA SILVA, 2006). 
Os quatro distritos pesquisados destacaram-se em todo o período de estudo, por situarem-se entre os que apresentaram as mais elevadas taxas de incidência e de mortalidade por TB no município ${ }^{7}$. Tal situação pode, ao menos em parte, ser explicada pelo fato de nele residirem estratos de classe média baixa, onde os Índices de Desenvolvimento Humano são inferiores à média do município (PMSP, 2000).

Os resultados apresentados apontam nos distritos estudados, a participação crescente, em termos absolutos e relativos, de pacientes de TB originários da Bolívia. Em 2008, somente em um dos distritos estudados, o do Brás, a proporção de casos entre bolivianos não superava a de brasileiros, mas era superior a $40 \%$ dos casos conhecidos. Neste mesmo ano, a taxa de incidência no conjunto desses distritos superava em 3,5 vezes a incidência média do município de São Paulo. No período analisado, não verificamos alterações expressivas na incidência de TB na área de estudo, porem, enquanto que o número absoluto de casos entre brasileiros diminuiu quase pela metade, entre os bolivianos, o aumento foi de $250 \%$.

Tais dados sugerem fortemente o potencial impacto das correntes migratórias recentes originárias de áreas hiperendêmicas no comportamento da TB no município de São Paulo, especialmente se considerarmos que estudamos somente quatro dos 19 distritos do município onde a presença migratória é reconhecida.

Além desses dados globais, foi possível apontar as principais características dos pacientes de TB da comunidade boliviana e algumas diferenças em relação aos brasileiros acometidos pela mesma doença.

A migração boliviana em São Paulo difere em alguns pontos de outras correntes migratórias que se deslocam para países industrializados, pois estas últimas, geralmente, se concentram em áreas muito pobres e possuem índice de desemprego bem maior que a população local. Os bolivianos no município de São Paulo apresentam forte inserção na indústria de confecção, com baixo nível de desemprego (CYMBALISTA e XAVIER, 2007) e concentram-se, principalmente, em distritos de classe média baixa, localizados em áreas

\footnotetext{
${ }^{7}$ Fonte: EPITB (1998-2005); TBWEB (2006-2008), acessado em 16/06/2010
} 
centrais do município, contanto com boa infra-estrutura urbana e fácil acesso a serviços de saúde e ao ensino.

Várias características dos pacientes de origem boliviana apresentam-se distintas se comparadas às dos brasileiros residentes nos mesmos distritos. Os bolivianos são mais jovens e a participação masculina é proporcionalmente menor, característica também observada em casos notificados de TB na Bolívia onde a proporção de homens com TB é semelhante a proporção de casos masculinos de TB nos distritos estudados (MINISTÉRIO DE SALUD Y DEPORTES, 2007).

Além disso, a taxa de desempregados e a prevalência de comorbidades são expressivamente inferiores.

Dado que a imigração boliviana é tipicamente laboral, grande parte dos imigrantes vem com o objetivo de trabalhar na indústria de confecção em São Paulo, essa situação define algumas características sócio-demográgicas desses bolivianos, que em sua maioria é jovem, com um nível de escolaridade semelhante a dos brasileiros residentes na mesma área, mas com baixa qualificação profissional (CYMBALISTA e XAVIER, 2007; PATARRA e BAENINGER, 2006).

Como a TB entre brasileiros apresenta as características de áreas de média endemicidade, verifica-se tendência de deslocamento da doença para as faixas etárias mais elevadas, característica resultante da redução do risco de infecção na comunidade (CHAIMOWICZ, 2001). A TB no Brasil ocorre em população mais velha, essa característica explica, em parte, a maior prevalência de co-morbidades em brasileiros.

O fato, dos bolivianos apresentarem baixa prevalência de co-infecção TB/HIV, deve-se provavelmente a pequena disseminação da AIDS naquele país, onde a incidência dessa doença é das mais baixas das Américas (USAID Bolívia, 2008).

Ainda com referência a co-morbidades, cabe ressaltar que a baixa prevalência de alcoólicos e de doenças mentais entre os pacientes imigrantes deve estar relacionada também às características da imigração laboral, enquanto que, a menor prevalência de diabetes decorreria do fato desse grupo de migrantes ser mais jovem que a população brasileira. 
Vários estudos assinalam a existência de critérios estabelecidos pelos países receptores de correntes migratórias, em relação às condições de saúde de imigrantes, o que explicaria o fato de, com freqüência, os imigrantes serem mais saudáveis do que os trabalhadores nativos do país receptor (MUENNING e FAHS, 2002; NEWBOLD e DANFORTH, 2003; READ e EMERSON, 2005). Os resultados apresentados por esta pesquisa são consistentes com os estudos citados.

Esta mesma linha de raciocínio talvez explique o fato de os bolivianos terem menor proporção de histórico anterior de TB se comparada aos brasileiros. No entanto, não se pode deixar de assinalar que os dados sugestivos de melhores condições de saúde entre os bolivianos, poderiam ser explicados por um viés decorrente do menor acesso aos serviços de saúde entre parcelas de migrantes mais pobres e menos integrados a sociedade local (MACDONALD e KENNEDY, 2004).

Um resultado importante e que merece destaque em relação ao desempenho do programa de controle da TB, é o fato de não ter sido encontrado sinais sugestivos de falta de equidade no acesso aos serviços ou na qualidade do atendimento oferecido aos bolivianos se comparados aos conferidos aos brasileiros.

As taxas de cura, de abandono, recidivas e de óbito, apresentam desempenho mais favorável entre os bolivianos, inclusive a proporção de submetidos ao tratamento supervisionado é mais elevada entre estes últimos.

A melhor compreensão desses dados merece estudos mais detalhados, pois tais resultados, até certo ponto inesperados, não refletem políticas públicas específicas. No entanto, sugerem que as diretrizes de promoção da equidade em saúde que constitui um dos fundamentos do Sistema Único de Saúde (SUS), pode se fazer sentir mesmo na ausência de políticas que tenham como foco populações vulneráveis, como é o caso da comunidade boliviana que vive no município de São Paulo.

A constituição federal de 1988 instituiu princípios e diretrizes para a reorganização do Sistema de Saúde vigente, formalizando o princípio igualitário e o comprometimento público com o objetivo de garantir a equidade. Dessa forma o SUS foi criado baseado nos princípios da universalidade e equidade, porém a instabilidade administrativa em algumas instâncias de poder (Federal, 
estadual ou municipal) e a insuficiência de recursos pode criar barreiras à observação desses princípios, o que torna importante a definição de políticas públicas específicas (MENICUCCI, 2009).

Provavelmente as modificações introduzidas em 1998 pelo Ministério da Saúde ao lançar o Plano Nacional de Combate à Tuberculose (PNCT) e em 2000 criando o Plano Nacional para o Controle da Tuberculose por meio da atenção básica (HIJJAR et al, 2007), também tenham criado condições favoráveis ao melhor desempenho do programa em populações vulneráveis. Essas modificações permitiram que as ações do PNCT passassem para a responsabilidade dos municípios, privilegiando as unidades de saúde de nível primário como as UBS, Programa de Saúde da Família e ambulatórios (RUFFINO-NETO e VILLA, 2006).

Talvez o aumento da adesão de imigrantes no período se deva a elevação da cobertura do PNCT e modificações de estratégias como a do tratamento supervisionado, a partir de 1998.

Políticas públicas específicas de promoção da equidade em saúde em comunidades de migrantes devem levar em considerações alguns pontos. $O$ aprimoramento do atendimento para comunidades de migrantes deve prever a adoção de atitudes que facilitem o acesso do paciente aos serviços de saúde, além dos incentivos, a qualidade de atendimento é um dos instrumentos aplicáveis para aumentar a adesão dos pacientes aos serviços de saúde. Incluindo, se necessário, horários especiais de funcionamento, pois a priori os serviços de saúde devem ser organizados de acordo com as necessidades dos pacientes (BAYER, 1995).

Alguns estudos indicam que a linguagem e comunicação constituem barreira para o atendimento e fornecimento de informações a estrangeiros que necessitam de atendimento médico, principalmente para aqueles imigrantes que estão no país há pouco tempo. Problemas de comunicação podem dar origem a mal-entendidos que não raro levam a resultado desfavorável do tratamento dificultando o acesso a serviços públicos de saúde àqueles que por motivos étnicos e culturais sentem dificuldades de expressar suas necessidades, essas dificuldades são particularmente graves para pacientes com problemas crônicos de saúde (MLADOVSKY, 2009). 
O princípio de equidade reconhece que os indivíduos são distintos entre si, merecendo, portanto tratamento diferenciado com o intuito de reduzir as desigualdades (VIANNA et al,2001), em vista disso, o não reconhecimento de que os imigrantes bolivianos necessitam de atendimento diferenciado em decorrência de seu idioma, etnia e cultura fere os princípios de equidade em saúde.

É importante ressaltar a necessidade de dados referentes à nacionalidade, naturalidade e etnia na ficha de notificação de doenças, esses dados são essenciais para vigilância epidemiológica oferecendo subsídios aos programas de saúde e para intervenções voltadas a promoção da equidade. A informação relativa à nacionalidade foi inserida na ficha de notificação da TB utilizada no Brasil, a partir de 2008, porém por ser de introdução recente, esse item nem sempre é preenchido adequadamente, além disso, muitas unidades de saúde utilizam fichas de notificação antigas para o preenchimento de dados, criando obstáculos para obtenção desses dados. A ausência ou mau preenchimento de dados sobre a etnia nos cuidados primário, secundário e terciário de saúde dificulta o planejamento de estratégias voltadas à ampliação do acesso aos serviços de saúde (MLADOVSKY, 2009).

Além disso, é recomendável a inclusão nos serviços de saúde de intérpretes profissionais em áreas com grande contingente de imigrantes, assim como serviços de educação, informação e materiais de comunicação adequados as diferentes necessidades de grupos minoritários. Assim como a inclusão de informações sobre o acesso aos serviços, direitos e educação sobre a TB e outras enfermidades (FIGUEROA-MUNOZ E RAMON-PARDO, 2008).

Além das atividades de controle da TB promovida pelos serviços primários de saúde, os imigrantes necessitam de intervenções adicionais, como o exame médico, orientação e aplicação de técnicas adequadas de rastreamento para algumas doenças, como é o caso da TB, no ponto de entrada para aqueles que entram regularmente no país (refugiados ou não). Tais medidas propiciariam condições mais favoráveis à inserção do migrante na sociedade do país receptor e menor impacto da introdução de doenças como a TB (FIGUEROA-MUNOZ E RAMON-PARDO, 2008). 
Atualmente o Brasil é um dos países que mais atraem imigrantes da América do Sul, devido a fatores econômicos e sociais, portanto é de vital importância que as políticas públicas brasileiras se adéqüem a essa nova realidade a fim de proporcionar $\mathrm{o}$ atendimento justo, portanto, equânime a todos. Os resultados apresentados sugerem um impacto não negligenciável dessas migrações nos indicadores de saúde em áreas do país que concentram essas correntes migratórias.

Os reflexos de processos migratórios no comportamento da TB têm sido assinalados em vários países desenvolvidos. O aumento das correntes migratórias a partir da década de 1980, originários de países com alta endemicidade de TB, inverteu a tendência de queda da incidência de TB em países industrializados (RIEDER, 1995). Atualmente, a proporção de imigrantes entre os casos notificados com TB excede $50 \%$ em muitos países europeus (INSTITUTE DE VEILLE SANITAIRE, 2007). A principal medida preventiva nesses países é a implementação de programas de triagem para os imigrantes no momento de chegada (RIEDER, 1994).

Em virtude do aumento de casos de TB associados à imigração, alguns países industrializados propõem medidas especiais de identificar e tratar indivíduos com infecção latente de TB, com foco especial a imigrantes provenientes de países aonde a TB é hiperendêmica (INSTITUTE OF MEDICINE, 2000; DERIEMER et al, 1998).

Alguns estudos sugerem que infecção do migrante após sua chegada ao país receptor é pouco freqüente, o que implica que a infecção, na maioria dos casos tenha ocorrido, no país de origem (DAHLE et al, 2001), além disso, o risco de ocorrência da TB é mais elevado durante os primeiros anos de imigração, mas pode permanecer assim elevado por vários anos após a chegada dos imigrantes (LILLEBAEK et al, 2002).

A interpretação dos resultados desta pesquisa deve ser feita considerando as limitações próprias de estudos utilizando dados de vigilância, como a subnotificação. Além disso, não podemos inferir os resultados para todo o município, ainda que não se espere grandes diferenças em relação aos demais distritos. Houve também, alguma dificuldade na identificação dos casos entre imigrantes bolivianos, pois a nacionalidade do paciente passa a ser registrada na ficha de notificação a partir de 2008, em vista disso o critério 
utilizado, para o período anterior, fundamentou-se na identificação dos sobrenomes étnicos dos povos oriundos da Bolívia.

Além dessas limitações, a ausência de dados que ofereçam 0 denominador para estimativas de risco entre esses migrantes, não nos permite uma avaliação precisa da magnitude e do impacto da migração boliviana na tendência dessa doença no município de São Paulo.

No entanto, apesar das limitações assinaladas, os resultados obtidos são consistentes e coincidem com os resultados do inquérito efetuado entre pacientes bolivianos em tratamento em UBS da área estudada. São úteis para melhor conhecer o perfil dos pacientes com TB na comunidade boliviana residente no município de São Paulo e as características da doença entre eles; mostra também a ausência de sinais de falta de equidade no acesso aos serviços e na qualidade do atendimento a eles oferecido, em comparação com a população local. Sugerem também que o cumprimento das diretrizes do Sistema Único de Saúde, de acesso universal aos serviços constitui instrumento efetivo de promoção da equidade em saúde, mesmo na ausência de políticas específicas para a população migrante. Por fim, os resultados obtidos poderão apoiar os gestores de saúde em ações voltadas a diminuir o impacto da presença da TB nessa comunidade e para a elaboração de políticas públicas específicas neste setor em questões relativas à migração. 


\section{CONSIDERAÇÕES FINAIS}

A pesquisa mediante entrevista realizada entre imigrantes bolivianos em tratamento de TB nas UBS existentes na área de estudo deve ser interpretada levando em conta que não se trata de uma amostra representativa. No entanto, os resultados obtidos são consistentes com os dados da vigilância, inclusive com referência às características sócio-demográficas. Indicaram, por exemplo, que a maioria dos pacientes bolivianos entrevistados durante o tratamento, em 2009, relatou boa qualidade de atendimento pelos profissionais de saúde, ainda que alguns tenham feito ressalvas, como falha na regularidade de distribuição dos medicamentos necessários e dificuldades na comunicação entre os profissionais de saúde pela barreira no idioma.

Oferecem também algumas informações interessantes como o fato de elevada proporção de pacientes estar há menos de três anos no Brasil e que parcela expressiva não mais retornou a Bolívia; cerca de metade deles refere outro caso na família previamente ao seu; enquanto reduzida proporção teve contato com outro caso de TB no local de trabalho. Considerando a carga de trabalho dessa população e aceitando-se o vínculo com reduzida rede social, que não vai além da família e dos colegas de trabalho, tais dados sugerem como origem da TB seja a reinfecção endógena ou a transmissão no ambiente familiar. Portanto, indica que o risco da doença no país de origem exerce forte influência no comportamento da TB nessa comunidade (VOS et al, 2004).

Por sua vez, a reduzida proporção de casos secundários no ambiente familiar, sugere algum impacto do diagnóstico e tratamento precoce e de outros indicadores de qualidade da assistência, como consultas mensais e as elevadas proporções daqueles que receberam tratamento supervisionado, se curaram no tempo preconizado de tratamento e receberem visitas domiciliares.

Aponta também na direção da qualidade do atendimento a elevada proporção dos entrevistados que utilizam a rede básica de serviços do SUS para resolver problemas de saúde. Os indicadores de cobertura e acesso a serviços de saúde entre os entrevistados são extremamente favoráveis, 73\% deles levam até 15 minutos e os $27 \%$ restantes entre 15 e 30 minutos para chegar à unidade de atendimento e parcela expressiva deles foi atendida no mesmo dia à época do diagnóstico da TB. 
Dos resultados apresentados e das informações disponíveis, ainda que incompletas, pode-se depreender que o Brasil vem se tornando um importante centro de atração migratória na América do Sul, África e de alguns países asiáticos (DA SILVA, 2006), mas ainda não definiu políticas públicas com referência a essa questão, especialmente aquelas voltadas à integração desse contingente de migrantes na sociedade brasileira.

Os resultados apresentados apontam na direção de importante impacto desse processo migratório nas condições de saúde de algumas áreas metropolitanas, como a de São Paulo e possivelmente em áreas de fronteira (MÁRMORA, 1997) especialmente com referência a algumas doenças infecciosas que apresentam forte vínculo com condições desfavoráveis de vida e com o subdesenvolvimento econômico, como é o caso da TB.

Outro aspecto diz respeito ao desempenho favorável do SUS como instrumento de promoção da equidade em saúde, mesmo na ausência de políticas públicas específicas, como é o caso do recente processo migratório que assistimos na última década. 


\section{CONCLUSÕES}

1) Entre janeiro de 1998 a dezembro de 2008, nos distritos administrativos do Belém, Bom Retiro, Brás e Pari, foram notificados 2434 casos de TB entre brasileiros e bolivianos. Dos quais 1644 (68\%) eram brasileiros e 740 bolivianos (30\%).

2) Durante esse período, os casos entre brasileiros diminuíram em $45 \%$ e entre bolivianos aumentou em $250 \%$ e a participação proporcional de casos de TB dos bolivianos elevou-se de $15 \%$ a $53 \%$.

3) Em 2008, a taxa de incidência de TB no conjunto de distritos pesquisado foi de 187/100.000 habitantes/ano, enquanto que, para o MSP, como um todo, se situaram em 53/100.000 habitantes/ano.

4) Os resultados mostram que o comportamento da TB na comunidade boliviana residente nos quatro distritos estudados contribuiu para a manutenção de elevadas taxas de incidências dessa doença na área de interesse.

5) Comparados aos brasileiros, os bolivianos eram mais jovens que os brasileiros (média: 26 versus 39 anos; $p<=0,0001$ ) e a prevalência de desemprego era mais baixa $(2,4 \%$ versus $10,4 \% ; p<0,0001)$.

6) Para o período de 2006 a 2008, comparados aos brasileiros, os bolivianos apresentaram taxas mais elevada de cura $(70,9 \%$ versus $62,1 \%$; $\mathrm{p}<0,001)$ e de tratamento supervisionado $(81,9 \%$ versus $62,2 \% ; \mathrm{p}<0,001)$ e menores de TB no passado (6,9\% versus $16,9 \% ; p<0,0001)$, abandono (16,9\% versus $22,4 \% ; p<0,001)$, de letalidade por TB $(1,6 \%$ versus $4,8 \%$; $p<0,001)$ e de recidiva $(4,9 \%$ versus $9,2 \% ; p<0,001)$.

7) Para o período de 2006 a 2008, comparados aos brasileiros, os bolivianos apresentaram prevalências mais baixas de co-morbidades, como a $\operatorname{AIDS}(0,7 \%$ versus $20,3 \% ; p<0,001)$, o diabetes $(1,4 \%$ versus $4,3 \%$; 
$p=0,033)$, o alcoolismo (2,4\% versus $15,1 \% ; p<0,001)$ e doença mental $(0 \%$ versus $1,2 \% ; p=0,059)$.

8) Não foram identificados sinais sugestivos e falta de equidade no acesso aos serviços ou na qualidade do atendimento aos pacientes da comunidade boliviana residentes nos quatro distritos estudados se comparadas a população local.

9) Os resultados do inquérito mostraram-se consistentes com os dados da vigilância, inclusive com referência às características sócio-demográficas e ao fácil acesso aos serviços e à qualidade do atendimento. 


\section{REFERÊNCIAS}

-Antunes JLF \& Waldman EA. The impact of AIDS, immigration and housing overcrowding on tuberculosis deaths in São Paulo, Brazil, 1994-1998. Soc Sci Med. 2001; 52(7): 1071-1080.

-ABEP (Associação brasileira de estudos de população) e UNFPA (Fundo de população das Nações Unidas). Brasil: 15 anos após a Conferência do Cairo, Campinas; 2009.

-Bayer R, Wilkinson D. Directly observed therapy for tuberculosis: history of an idea. Lancet.1995;345 (8964):1545-1548.

-Cacciamali MC, de Azevedo FAG. Entre o tráfico e a opção da mobilidade social: a situação dos imigrantes bolivianos na cidade de São Paulo. Cadernos PROLAM/USP. 2006; 1: 129-143.

-Carballo M, Nerukar A. Migration, refugees, and health risks. Emerg Infect Dis. 2001; 7 (3 Supl): 556-560.

-Carballo M. The challenge of migration and health. International Centre for Migration and Health (ICMH articles), 2007. [acessado em 27/03/2009]. Disponível_em:http://www.icmh.ch/WebPDF/2007/WHA\%20DISTRIBUTION\%2 OARTICLE\%2018_05_2007formatted.pdf

-Chaimowicz F. Age transition of tuberculosis incidence and mortality in Brazil. Rev Saúde Pública. 2001; 35 (1): 81-87.

-Clancy L, Rieder HL, Enarson DA, Spinaci S. Tuberculosis elimination in the countries of Europe and other industrialized countries. Eur Respir J. 1991; 4(10):1288-1295.

-Coelho AGV, Zamarioli LA, Perandones CA, Cuntiere I, Waldman EA. Characteristics of pulmonary tuberculosis in a hyperendemic area: the city of Santos, Brazil. J Bras Pneumol. 2009; 35 (10):998-1007.

-Corbett EL, Watt CJ, Walker N, Maher D, Williams BG, Raviglione MC, et al. The growing burden of tuberculosis: global trends and interactions with the HIV epidemic. Arch Intern Med. 2003; 163 (9):1009-1021. 
-Council of Europe. The adaptation of health care services to demand of health care and health care services of people in marginal situations. COE; 2001 [Acessada em 19/01/2009]. Disponível em: https://wcd.coe.int/ViewDoc.jsp?id=228725\&BackColorlnternet=9999CC\&Back ColorIntranet=FFBB55\&BackColorLogged=FFAC75]

-Cymbalista R, Xavier IR. A comunidade boliviana em São Paulo: definindo padrões de territorialidade. Cadernos metrópole. 2007; 2 (17): 119-133.

-Da Silva SA. Bolivianos em São Paulo: entre o sonho e a realidade. Estud av. 2006; 20 (57): 157-170

-Da Silva SA. Costurando sonhos: trajetória de um grupo de imigrantes bolivianos em São Paulo. São Paulo: Paulinas; 1997.

-Dahle UR, Sandven P, Heldal E, Caugant DA. Molecular epidemiology of Mycobacterium tuberculosis in Norway. J Clin Mcrobiol. 2001; 39 (5):18021807.

-DeRiemer K, Chin DP, Schecter GF, Reingold AL. Tuberculosis among immigrants and refugees. Arch Intern Med. 1998, 158(7):753-760.

-Dirección General de Inmigración y Cooperación al Desarrollo, Área de Gobierno de Familia y Servicios Sociales Ayuntamiento de Madrid. Plan Estratégico de actuación en Bolivia 2007-2010: Con la infancia y El fortalecimiento local. Madrid; 2007.

-Dye C, Scheele S, Dolin P, Pathania V, Raviglione M. Global burden of tuberculosis: estimated incidence, prevalence, and mortality by country: WHO GLOBAL Surveillance and monitoring project. JAMA. 1999; 282 (7): 677-686.

-Institute de veille sanitaire. Euro TB and the National Coordinators for TB surveillance in the WHO European region. Surveillance of tuberculosis in Europe: report on tuberculosis cases reported in 2005. França; 2007.

-Farah MG, Meyer HE, Selmer R, Heldal E, Bjune G. Long-term risk of tuberculosis among immigrants in Norway. Intern J Epidemiol. 2005; 34(5): 1005-1011.

-Fiúza de Melo FA, Afiune JB, Neto JI, De Almeida EA, Spada DTA, Antelmo ANL et al. Aspectos epidemiológicos da tuberculose multirresistente em serviço 
de referência na cidade de São Paulo. Rev Soc Bras Med Trop. 2003; 36 (1): 27-34.

-Figueroa-Munoz $\mathrm{JI}$, Ramon-Pardo P. Tuberculosis control in vulnerable groups. Bull World Health Organ. 2008; 86 (9): 733-735.

-Fonseca ML, Esteves A, McGarrigle J, Silva S. Saúde e integração dos imigrantes em Portugal: uma perspectiva geográfica e política. Migrações. 2007; (1): 27-53.

-Grove NJ, Zwi AB. Our health and theirs: forced migration, othering, and public health. Soc Sci Med. 2006; 62 (8):1931-1942.

- Hijjar MA, Gerhardt G, Teixeira GM, Procópio MJ. Retrospecto do controle da tuberculose no Brasil. Rev Saúde Pública. 2007;41 (Supl 1):50-58.

- Hijjar MA, Procópio MJ, de Freitas LMR, Guedes R, Bethlem EP. Epidemiologia da tuberculose: importância no mundo, no Brasil e no Rio de Janeiro. Pulmão RJ. 2005; 14(4) :310-314.

-Hisbello SC. Etiopatologia da tuberculose e formas clínicas. Pulmão RJ. 2006; 15(1):29-35.

-lanni AMZ, Quitério LAD. Promoção da saúde e meio ambiente no Programa de Saúde da Família: os casos da Barra Funda e Jardim Rio Claro, município de São Paulo. Rev Saúde Soc. 2004; 13(1): 81-91.

-Institute of medicine. Ending neglect: the elimination of tuberculosis in the United states. National academy press, 2000.

-Institute of Public Health. Guidelines for the prevention and control of tuberculosis [inNorwegian]. Oslo: Norwegian, 2002.

-Jansà JM. Salud y inmigración: nuevas realidades y nuevos retos. Gac Sanit. 2004; 18(Supl 1): 207-213.

-Keizer ST, Langendam MM, Van Deutekom H, Coutinho RA, Van Ameijden EJ. How does tuberculosis relate to HIV positive and HIV negative drug users? $J$ Epidemiol Community Health. 2000; 54(1): 64-68. 
-Lillebaek T, Andersen ÅB, Dirksen A, Smith E, Skovgaard LT, Kok- Jensen A. Persistent high incidence of tuberculosis in immigrants in a low-incidence country. Emerg Infect Dis. 2002; 8 (7):679-684.

-Lindoso AAB; Portela; Waldman EA; Komatsu NK; Figueiredo SM; Taniguchi M; Rodrigues LC. Profile of tuberculosis patients progressing to death, city of São Paulo, Brazil, 2002. Rev Saúde Pública 2008; 42(5): 641-648.

-MacPherson DW, Gushulak BD, Macdonald L. Health and foreign policy: influences of migration and population mobility. Bull World Health Organ. 2007; 85 (3): 200-206.

-Mármora L. Las políticas de migraciones internacionales. Madri/Buenos Aires.OIM/Alianza editorial. 1997.

-McDonald JT, Kennedy S. Insights into the 'healthy immigrant effect': healthy status and health service use of immigrants to Canada. Soc Sci Med. 2004; 59 (8):1613-1627.

-Menicucci TMG. O Sistema Único de Saúde, 20 anos: balanços e perspectivas. Cad saúde pública. 2009; 25 (7):1620-1625.

-Ministério da Justiça.[homepage na internet] [Acessada em 23/03/10]. Disponívelem:http://portal.mj.gov.br/data/Pages/MJA5F550A5ITEMIDBA915BD 3AC384F6C81A1AC4AF88BE2D0PTBRIE.htm

-Ministério da Saúde. Programa Nacional de Controle da Tuberculose. Bol Pneumol Sanit.1996;4:7-56.

-Ministério da Saúde. Secretaria de Vigilância em Saúde. Guia do Programa de Vigilância Epidemiológica da tuberculose multirresistente (Versão Preliminar). Rio de Janeiro: MS, 2005.

-Ministério da saúde/SVS. Sistema de informação de agravos de notificação. Sinan net.[homepage da internet] [Acessado em: 02/05/10]. 2009. Disponível em: http://dtr2004.saude.gov.br/sinanweb/index.php

-Ministério da Saúde/SVS - Sistema de Informação de Agravos de Notificação Sinan Net . [Acessado em: 14/07/2010]. 2008. Disponível em: http://dtr2004.saude.gov.br/sinanweb/index.php 
-Ministério de Salud y Deportes. Boletín de epidemiologia, 2007: 4 (3).

-Ministerio de Salud y Deportes. Boletín informativo epidemiológico. Dirección general de salud. Unidad de epidemiologia. 2007;4(3).

-Ministério de Salud y Deportes. Informe gestión 2002. Dirección general de control y prevención de enfermedades. Programa nacional de control de la tuberculosis, La Paz, Bolívia. 2002.

-Mladovsky P. A framework for a analyzing migrant health policies in Europe. Health Policy. 2009; 93 (1): 55-63.

-Muenning P, Fahs MC. Health status and hospital utilization of recent immigrants to New York City. Prev Med. 2002; 35 (3): 225-231.

-Nachega JB, Chaisso RE. Tuberculosis drug resistance: a global threat. Clin Infect Dis. 2003; 36 (Supl 1) : 24-30.

-Newbold KB, Danforth J. Health status and Canada's immigrant population. Soc Sci Med.. 2003; 57(10):1981-1995.

-Patz D, Millán JC, Mazín R, Ramón P, Rodríguez R, Cruz R, Gómez H. Construyendo paso a paso: guía sobre atención integral de personas que viven com la coinfección de TB/VIH en América Latina y el Caribe. Organización panamericana de salud. 2003.

-Parlamento Europeu. EU annual report on human rights; 2006. [Acessada em 16/07/07]. Disponível em: http://ec.europe.eu/external relations/library/publications/31 2006 eu human rights_en.pdf

-Patarra NL, Baeninger R. Migrações internacionais, globalização e blocos de integração econômica: Brasil no MERCOSUL. In: I Congresso de Associação Latino Americana de população; 2004; Caxambu, BR. São Paulo: Associação Latino-Americana de população (ALAP).

-Patarra NL. Migrações internacionais de e para o Brasil: volumes, fluxos, significados e políticas. São Paulo em Perspectiva. 2005; 19 (3): 23-33.

-Patarra NL, Baeninger R. Mobilidade espacial da população no MERCOSUL: metrópoles e fronteiras. Rev Bras Ci Soc. 2006; 21(60)(Supl 60) : 84-181. 
-PMSP. Secretaria Municipal do Desenvolvimento, Trabalho e Solidariedade (SDTS), 2000.

-PNCT Bolívia. Programa Nacional de Control de la Tuberculosis. 2005. Acessada em 01/05/10]. Disponível em: http://www.sns.gov.bo/tuberculosis/Areas/Estadistica/Cohortes/Cohorte.aspx -Ponciano L. Bairros paulistanos de A a Z. São Paulo: SENAC; 2001. -Prefeitura de São Paulo.[Acessada em 23/03/10]. Disponível em: http://www.prefeitura.sp.gov.br/portal/a_cidade/noticias/index.php?p=28087 -Read JG, Emerson MO. Racial context, black immigration and the US black/white health disparity. Soc forces. 2005; 84 (1):181-199.

-Reijneveld S. Reported health, lifestyles and use of health care of first generation immigrants in the Netherlands: do socioeconomic factors explain their adverse position? J Epidemiol Community Health. 1998; 52 (5): 298-304.

-Reis RR.. Soberania, direitos humanos e migrações internacionais. Rev Bras Ci Soc. 2004; 19 (55):150-162.

-Rieder HL, Zellweger JP, Raviglione MC, Keizer ST, Migliori GB. Tuberculosis control in Europe and international migration. Eur Respir J. 1994;7(8):15451553.

-Rieder HL. Epidemiology of tuberculosis in Europe. Eur Respir J. 1995; 20 (6):20-32.

-Rossetti MLR, Valim ARM, Silva MSN, Rodrigues VS. Tuberculose resistente: revisão molecular. Rev Saúde Pública. 2002; 36 (4): 525-532.

-Ruffino-Netto A. Impacto da reforma do setor saúde sobre os serviços de tuberculose no Brasil. Bol Pneumol Sanit. 1999; 7(1): 7-18.

-Ruffino-Netto A. Tuberculose: a calamidade negligenciada. Rev Soc Bras Med Trop. 2002; 35 (1): 51-58.

-Ruffino-Netto A, Villa TCS. A implantação do DOTS em algumas regiões do Brasil: histórico e peculiaridades regionais. Ribeirão Preto: Instituto Milênio/Rede TB. 2006: 75-139. 
-Santoro-Lopes G, Pinho AM, Harrison LH, Schechter M. Reduced risk of tuberculosis among Brazilian patients with advanced human immunodeficiency virus infection treated with highly active antiretroviral therapy. Clin Infect Dis. 2002; 34 (4):543-546.

-Sarriera JC, Oliveira APS, Hofstaetter $\mathrm{CH}$, Hermel JS. O processo de integração de imigrantes hispano-americanos: análises e perspectivas. PSICO ч. 2005; 36(1): 73-80.

-Secretaria de Vigilância em Saúde, Ministério da Saúde. Sistema nacional de vigilância em saúde: relatório de situação. Espírito Santo; 2006.

-Silveira JM, Sassi RAM, Oliveira Netto IC, Hetzel JL. Prevalência e fatores associados à tuberculose em pacientes soropositivos para o vírus da imunodeficiência humana em centro de referência para tratamento da síndrome da imunodeficiência adquirida na região sul do Rio Grande do Sul. J Bras Pneumol. 2006; 32(1):48-55.

-Stronks K, Ravelli A, Rejineyveld AS. Immigrants in the Netherlands: equal access for equal needs? J Epidemiol Community Health. 2001; 55: 701-70.

-Tamsma N, Berman PC. The role of the health care sector in tackling poverty and social exclusion in Europe. European health management association (EHMA); 2004. [Acessado em 20/03/2009]. Disponível em: http://www.healthinequalities.org/bot_Seite2111.html

-Théry H. Migrações internacionais e populações estrangeiras na França e no Brasil. Mercator. 2009; 8 (16): 7-18.

-Travassos C. Equidade e o sistema único de saúde: uma contribuição para debate. Cad Saúde Pública.1997; 13(2): 325-330.

-URB AL rede 10, Instituto UNIEMP, Prefeitura do Município de São Paulo. A imigração na cidade de São Paulo: integração dos imigrantes na cidade como forma de combate à pobreza. São Paulo; 2007.

-USAID Bolívia. HIV-AIDS health profile, 2008 [Acessado em 15/12/2009]. Disponível em: http://bolivia.usaid.gov/ 
-USAID. Diagnóstico de la situación de la tuberculosis en dieciséis municípios priorizados de Bolivia. Documento interno técnico de los proyectos GCS y QAP. 2007. 26 p.

-Vargas I, Vazques ML, Jane E. Equity and health system reform in Latin America. Cad Saúde Pública. 2002; 18 (4): 927-937.

-Viana ALD, Fausto MCR, De Lima LD. Política de saúde e equidade. São Paulo em perspectiva. 2003; 17(1): 58-68.

-Vianna SM, Nunes A, Barata RB, Santos JRS. Medindo as desigualdades em saúde no Brasil: uma proposta de monitoramento. Organização Pan-americana da saúde, Brasília, 2001, 224p

-Vieira RCA, Fregona G, Palaci M, Dietze R, Maciel ELN. Perfil epidemiológico dos casos de tuberculose multirresistente no Espírito Santo. Rev Bras Epidemiol. 2007; 10 (1): 56-65.

-Vos AM, Meima A, Verver S, Looman CWN, Bos V, Borgdorff MW, Habbema JDF. High incidence of pulmonary tuberculosis persists a decade after immigration, the Netherlands. Emerg Infect Dis. 2004; 10 (4): 736-739.

-Whalen CC, Nsubuga P, Okwera A, Johnson JL, Hom DL, Michael NL, et al. Impact of pulmonary tuberculosis on survival of HIV-infected adults: a prospective epidemiologic study in Uganda. AIDS. 2000; 14 (9): 1219-1228.

-WHO Regional Office for Europe. Targets for health for all. Copenhagen.1985.

-WHO report 2009. Global tuberculosis control: epidemiology, strategy, financing; 2009.

-WHO - World Health Organization. Otawa Charter for Health Promotion. Geneva; 1986.

-Who.int [homepage da internet] New York: World Health Organization. Disponível em: http://www.who.int/gtb/Country_info/index.htm.

-WHO.int. TB cowntry profile: Bolivia. 2007. [Acessada em: 30/04/10] Disponívelem:HTTP://apps.who.int/globalatlas/predefineReports/TB/PDF_Files/ bol.pdf 
-WHO-World Health Organization. Implementing the WHO stop TB strategy: a handbook for national tuberculosis control programes. Geneva; 2008.

-Woortmann EF. Japoneses no Brasil/brasileiros no Japão: tradição e modernidade. Rev antropologia.1995; 38(2): 7-34.

-Wolffers I, Verghis S, Marin M. Migration, human rights, and health. Lancet. 2003; 362 (9400): 2019-2020.

-World Health Organization. Global tuberculosis control. WHO Report2000.WHO/CDS/2000-275.

-World Health Organization. Global tuberculosis control: surveillance, planning, financing. Geneva: World Health Organization; 2007

-World Health Organization. Global tuberculosis control: surveillance, planning, financing. Geneva: World Health Organization; 2006. 


\section{Apêndice I}

\section{Projeto}

\section{EQUIDADE EM SAÚDE: O CASO DA TUBERCULOSE NA COMUNIDADE DE BOLIVIANOS NO MUNICÍPIO DE SÃO PAULO}

Questionário a ser aplicado em entrevista com o paciente (Confidencial)

Data da entrevista:

Entrevistador:

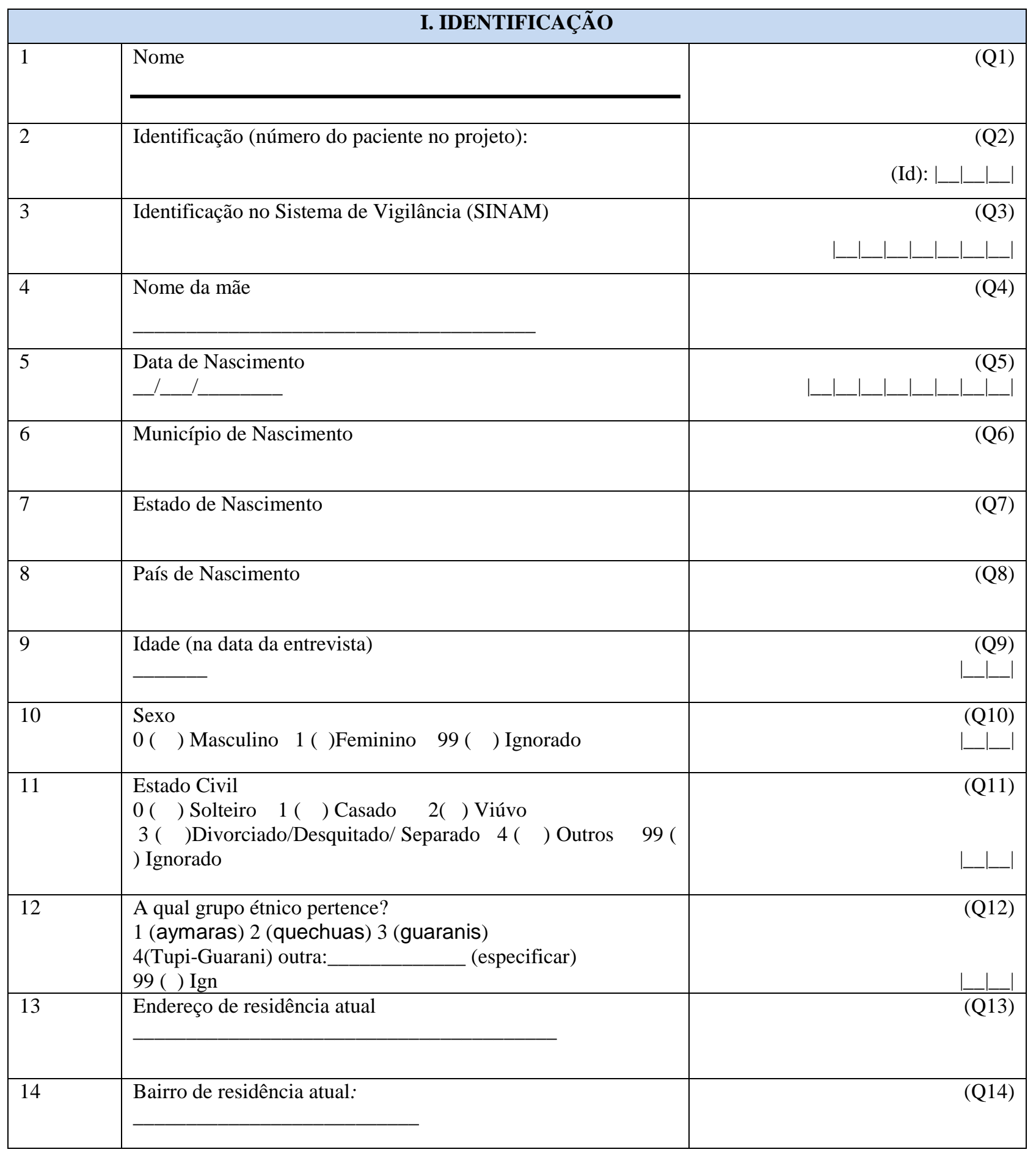




\begin{tabular}{|c|c|c|}
\hline 15 & $\begin{array}{l}\text { CEP da residência atual: } \\
---------\end{array}$ & $\mid$ \\
\hline 16 & Telefone para contato & |_|_||_|__|___||_|_| \\
\hline 17 & Município de residência atual: & (Q17) \\
\hline 18 & Data de chegada no Brasil & $(\mathrm{Q} 18)$ \\
\hline 19 & $\begin{array}{l}\text { Frequiência em que visita seu país de origem } \\
0 \text { ( ) } 1 \text { vez por ano } \\
1 \text { ( ) mais de uma vez por ano } \\
2 \text { ( ) } \quad \text { (especificar) }\end{array}$ & $\begin{array}{l}(\mathrm{Q} 19) \\
\left|\_\right| \_\mid\end{array}$ \\
\hline 20 & Escolaridade (em anos completos de estudo formal) & $\begin{array}{l}(\mathrm{Q} 20) \\
\left|\_\right| \_\mid\end{array}$ \\
\hline 21 & Ocupação no início da doença & $(\mathrm{Q} 21)$ \\
\hline 22 & Ocupação atual & $(\mathrm{Q} 22)$ \\
\hline \multicolumn{3}{|c|}{ II. HABITAÇÃO } \\
\hline 23 & 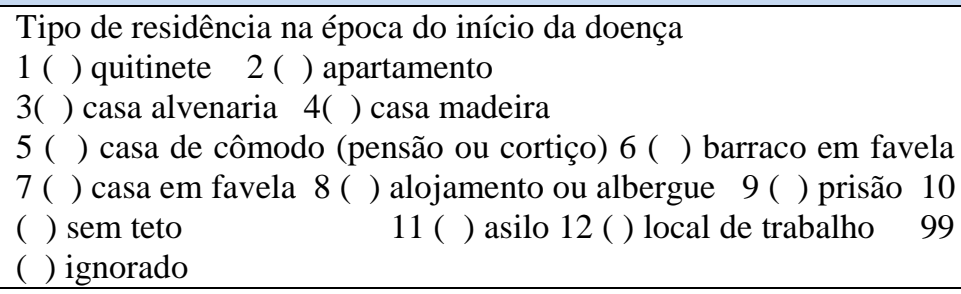 & $\begin{array}{l}(\mathrm{Q} 23) \\
\left|\_\right| \_\mid\end{array}$ \\
\hline 24 & Quantas pessoas residem nesse endereço: & $(\mathrm{Q} 24)$ \\
\hline 25 & 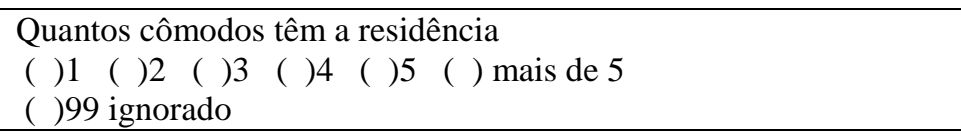 & $\begin{array}{l}(\mathrm{Q} 25) \\
\left|\_\right| \_\mid\end{array}$ \\
\hline 26 & $\begin{array}{l}\text { Número de pessoas por cômodo } \\
\begin{array}{ll}\text { ( ) } 1 \text { ( ) } 2 \text { ( ) } 3 \text { ( ) } 4 \text { ( ) } 5 \\
\text { ( ) mais de } 5 \text { ( ) } 99 \text { ignorado }\end{array}\end{array}$ & $\begin{array}{l}(\mathrm{Q} 26) \\
\left|\_\right| \_\mid\end{array}$ \\
\hline 27 & $\begin{array}{l}\text { Condição de ocupação } \\
\text { ( )1 alugada ( } 2 \text { própria ( )3 cedida } 4(\text { ) outros } 99 \text { ( ) } \\
\text { ignorado }\end{array}$ & $\begin{array}{l}(\mathrm{Q} 27) \\
\left|\_\right| \_\mid\end{array}$ \\
\hline 28 & Média salarial & $(\mathrm{Q} 28)$ \\
\hline 29 & Horas de trabalho & $(\mathrm{Q} 29)$ \\
\hline \multicolumn{3}{|c|}{ III. HISTÓRIA PREGRESSA } \\
\hline 30 & $\begin{array}{l}\text { Foi vacinado com BCG intradermico? } \\
\begin{array}{llll}\text { ( ) Não } & 1(\text { ) Sim } & 99 \text { ( ) Ignorado }\end{array}\end{array}$ & $\begin{array}{ll}(\mathrm{Q} 30) \\
|+| \_\mid\end{array}$ \\
\hline
\end{tabular}




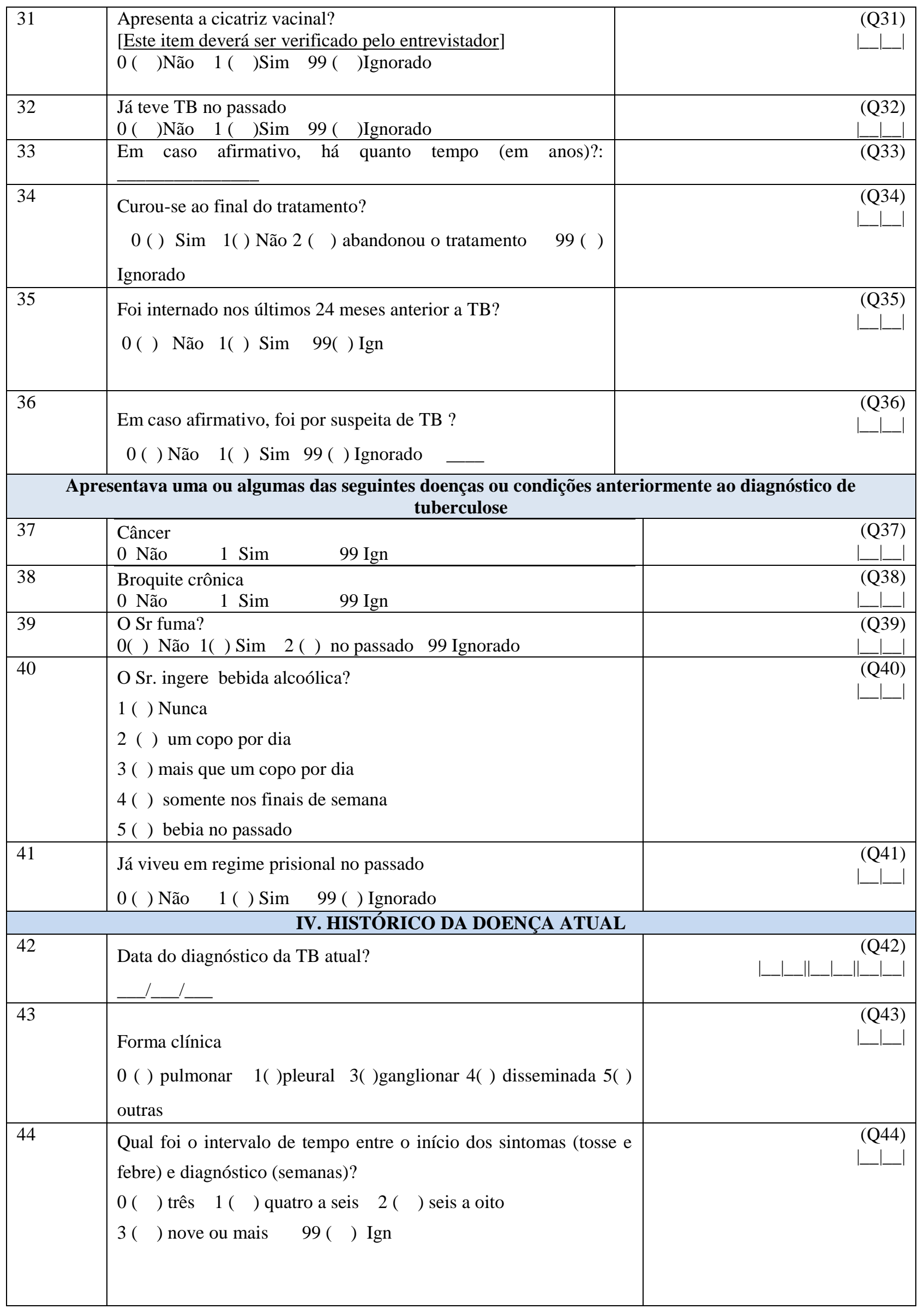




\begin{tabular}{|c|c|c|}
\hline 45 & $\begin{array}{l}\text { Qual foi o intervalo de tempo entre diagnóstico e tratamento (em } \\
\text { semanas)? } \\
\begin{array}{ll}0(\text { ) uma } 1(\text { ) duas a três } & 2(\text { ) quatro } \\
3(\text { ) quatro ou mais } 99() \text { Ign }\end{array}\end{array}$ & $\begin{array}{l}\text { (Q45): } \\
\text { |____ }\end{array}$ \\
\hline 46 & $\begin{array}{l}\text { País onde foi feito o diagnóstico } \\
0(\text { ) Brasil } \quad 1 \text { ( ) Bolívia } 2 \text { ( ) outro }\end{array}$ & $(\mathrm{Q} 46)$ \\
\hline 47 & $\begin{array}{l}\text { Em qual tipo de assistência médica foi feito o diagnóstico? } \\
\text { 1( ) Hospital } \\
2 \text { ( ) Ambulatório } \\
3 \text { ( ) Pronto Socorro } \\
4 \text { ( ) Unidade Básica de Saúde } \\
\text { 99( ) Ignorado }\end{array}$ & $(\mathrm{Q} 47)$ \\
\hline \multicolumn{3}{|c|}{ Sintomas presentes no momento do diagnóstico } \\
\hline 48 & $\begin{array}{l}\text { Febre } \\
0(\text { ) Não 1( ) Sim } 99(\text { ) Ign }\end{array}$ & $\left(\begin{array}{l}Q 48) \\
\left|\_\right| \_\mid\end{array}\right.$ \\
\hline 49 & 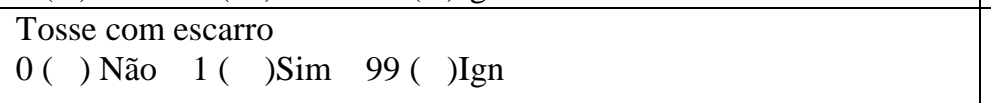 & $\begin{array}{l}(\mathrm{Q} 49) \\
\left|\_\right|+\mid\end{array}$ \\
\hline 50 & 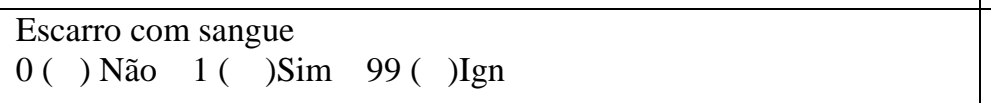 & $\begin{array}{l}(\mathrm{Q} 50) \\
\left|\_\right| \ldots \mid\end{array}$ \\
\hline 51 & $\begin{array}{l}\text { Perda de peso } \\
0(\text { ) Não } 1(\text { ) Sim } 99(\text { ) Ign }\end{array}$ & 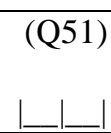 \\
\hline \multicolumn{3}{|c|}{ V. TRATAMENTO } \\
\hline 52 & $\begin{array}{l}\text { Antes do início da sua doença, outro familiar já apresentava TB?0 } \\
\text { ) Não } 1(\text { )Sim } 99 \text { ( }\end{array}$ & $\begin{array}{l}(\mathrm{Q} 52) \\
\left|\_\right|-\mid\end{array}$ \\
\hline 53 & $\begin{array}{l}\text { Antes do início da sua doença, algum colega de trabalho já } \\
\text { apresentava TB? } \\
0(\text { ( ) Não } 1(\text { ( ) Sim } 99(\text { ( ) Ign }\end{array}$ & (Q53) \\
\hline 54 & $\begin{array}{l}\text { Após o diagnóstico de sua doença foi identificado outro caso de } \\
\text { tuberculose na família? } \\
0 \text { ( )Não 1( )Sim, trabalho } 2 \text { ( ) sim, família } \\
99 \text { ( )Ignorado }\end{array}$ & $\begin{array}{l}(\mathrm{Q} 54): \\
|+|\end{array}$ \\
\hline 55 & $\begin{array}{l}\text { Após o diagnóstico a família recebeu uma visita da equipe do } \\
\text { centro de saúde } \\
0(\text { Não } 1(\text { ) Sim } 99(\text { ) Ignorado }\end{array}$ & $\begin{array}{l}(\mathrm{Q} 55) \\
\left|\_\right|+\mid\end{array}$ \\
\hline 56 & $\begin{array}{l}\text { Qual a freqüência de consultas durante o tratamento? } \\
\begin{array}{llll}(\quad) \text { mensal } 1(\quad) \text { bimestral } & \text { 2. ( ) trimestral } & 99() \\
\text { ignorado } & & \end{array}\end{array}$ & $\begin{array}{l}\text { (Q56): } \\
\left|\_\right|+\mid\end{array}$ \\
\hline 57 & 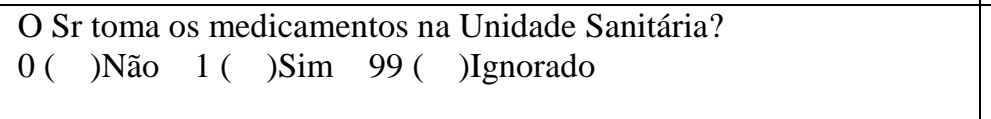 & (Q57): \\
\hline 58 & $\begin{array}{l}\text { Em caso afirmativo, quantas vezes por semana? } \\
\begin{array}{llllll}0() 1 & 1() 2 & 2() 3 & 3() 4 & 4() 5 & 5(\text { ) mais de } 5\end{array}\end{array}$ & 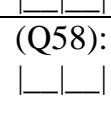 \\
\hline 59 & $\begin{array}{l}\text { Como foi o atendimento que recebeu na unidade de saúde } \\
0(\text { )atencioso } 1(\text { ) normal } 2(\quad) \text { pouco atencioso } 99(\text { ) } \\
\text { Ign }\end{array}$ & $\begin{array}{l}(\mathrm{Q} 59) \\
\left|\_\right| \_\mid\end{array}$ \\
\hline
\end{tabular}




\begin{tabular}{|c|c|c|}
\hline \multicolumn{3}{|c|}{ V. CONDUTA } \\
\hline 60 & $\begin{array}{l}\text { Qual centro de atendimento o Sr(a). busca quando necessita de } \\
\text { algum controle de saúde preventivo } \\
\text { ( vacinação BCG, exames de escarro, etc) } \\
\text { 1( ) Hospital 2( )Ambulatório } 3 \text { ( )Pronto Socorro } \\
\text { 4 ( ) Unidade Básica de Saúde } 5 \text { ( ) Centro de saúde } \\
\text { 99 ( )Ign }\end{array}$ & $\begin{array}{l}(\mathrm{Q} 60) \\
\left|\_\right|+\mid\end{array}$ \\
\hline \multirow[t]{2}{*}{61} & $\begin{array}{l}\text { Quando o } \operatorname{Sr}(a) \text { precisa consultar um especialista qual centro de } \\
\text { atendimento procura primeiro para ser encaminhado }\end{array}$ & \multirow[t]{2}{*}{$(\mathrm{Q} 61)$} \\
\hline & $\begin{array}{l}\text { 1( ) Hospital 2( )Ambulatório } \\
3 \text { ( )Pronto Socorro } 4 \text { ( ) Unidade Básica de Saúde } \\
5 \text { ( ) Centro de saúde } 99 \text { ( )Ign }\end{array}$ & \\
\hline \multirow[t]{2}{*}{62} & O Sr(a) tem direito ao atendimento médico nas UBS & (Q62) \\
\hline & 0 ( ) Sim 1( ) Não 2() Não sei & $\mid$ \\
\hline \multicolumn{3}{|c|}{ VI. ACESSO } \\
\hline 63 & $\begin{array}{l}\text { Como o Sr.(a) vai para as consultas: } \\
\text { ( ) ônibus } 1(\text { ) metro } 2(\text { ) carro } \\
3(\text { ) a pé } 4(\text { ) outro }\end{array}$ & $\begin{array}{l}\text { (Q63): } \\
\left|\_\right|+\mid\end{array}$ \\
\hline 64 & 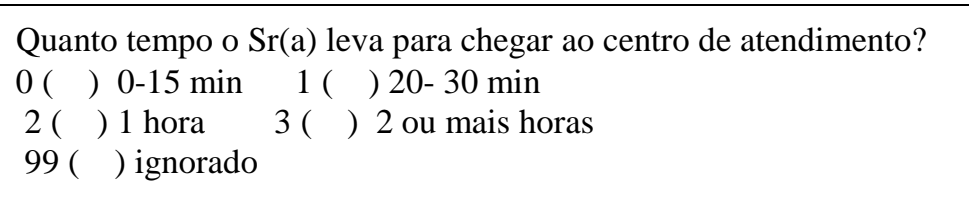 & (Q64): \\
\hline 65 & $\begin{array}{l}\text { Quando o } \mathrm{Sr}(\mathrm{a}) \text { vai ao centro de atendimento com os sintomas de } \\
\text { TB qual foi o prazo de atendimento } \\
0 \text { ( ) no mesmo dia } 1(\quad) 24 \text { horas depois } \\
2 \text { ( ) mais de } 24 \text { horas depois }\end{array}$ & $\begin{array}{l}(\mathrm{Q} 65): \\
\left|\_\right|+\mid\end{array}$ \\
\hline 66 & $\begin{array}{l}\text { O Sr(a) paga o transporte para realizar o tratamento de TB } \\
0\left(\begin{array}{lll}\quad) \operatorname{sim} & 1( & \text { ) não }\end{array}\right.\end{array}$ & (Q66): \\
\hline 67 & $\begin{array}{l}\text { Durante o tratamento houve falta de medicamento para TB } \\
0(\quad) \operatorname{sim} \quad 1(\quad) \text { não }\end{array}$ & (Q67): \\
\hline 68 & $\begin{array}{l}\text { Quanto tempo o } \mathrm{Sr}(\mathrm{a}) \text { espera para ser atendido } \\
0 \text { ( ) entre } 15 \mathrm{~min} \text { e } 30 \mathrm{~min} 1 \text { ( ) entre } 30 \text { e } 60 \mathrm{~min} \\
2 \text { ( ) mais de } 60 \mathrm{~min}\end{array}$ & 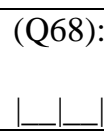 \\
\hline 69 & $\begin{array}{l}\text { O Sr tem dificuldade em ser compreendido pelos profissionais de } \\
\text { saúde (auxiliares)?0( ) S 1( ) não }\end{array}$ & 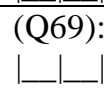 \\
\hline 70 & $\begin{array}{l}\text { O Sr. Tem dificuldade em ser compreendido pelos médicos? } \\
0\left(\begin{array}{lll}(\quad) \operatorname{sim} & 1(\quad \text { não }\end{array}\right.\end{array}$ & (Q70): \\
\hline 71 & $\begin{array}{l}\text { O senhor entende a orientação dada pelos profissionais de saúde? } \\
0\left(\begin{array}{lll}(\quad) \operatorname{sim} & 1(\quad) \text { não }\end{array}\right.\end{array}$ & $(Q 71)$ \\
\hline
\end{tabular}




\title{
Apêndice II
}

\section{CONSENTIMENTO LIVRE E ESCLARECIDO}

\author{
Dados sobre a pesquisa: \\ Título do Projeto: Equidade em saúde: $O$ caso da tuberculose na comunidade de bolivianos do \\ município de São Paulo \\ Pesquisador: Vanessa Nogueira Martinez - tel: 2942-8086 \\ Coordenador do projeto: Prof Dr Eliseu Alves Waldman - Dep. Epidemiologia da Faculdade de Saúde \\ Pública da USP Av Dr Arnaldo 715, Cerqueira César, SP/SP- \\ Tel: 3061-7109
}

A tuberculose é uma doença causada por uma bactéria que se espalha pelo ar e seu contágio ocorre de pessoa para pessoa através da tosse, espirro ou da fala em voz alta do doente. Geralmente essa bactéria ataca os pulmões e seus principais sintomas são tosse por mais de três semanas, além de febre, suores noturnos e perda de peso. Apesar de ser uma doença curável, quando tratada adequadamente, e de fácil diagnóstico ainda existe muitas mortes ocasionadas por essa doença. O objetivo desse estudo é de investigar alguns fatores que podem dificultar a cura dos pacientes, com isso poderemos contribuir para a melhoria nas ações destinadas ao controle da tuberculose, facilitando a diminuição de casos e mortes causadas pela tuberculose no Brasil.

A sua participação no estudo colabora com a descrição dos fatores de risco para a tuberculose na comunidade boliviana do município de São Paulo, pois devido ao estilo de vida de muitos imigrantes essa população se torna vulnerável à doença.

Esse estudo poderá trazer benefícios à comunidade de imigrantes no município de São Paulo, auxiliando na elaboração de políticas públicas específicas relativas à melhoria do acesso, controle da doença na comunidade e a melhora do relacionamento entre profissionais da saúde e imigrantes latino-americanos, condições essenciais ao tratamento adequado da doença. Declaro que esse estudo não causará nenhum desconforto ou risco ao entrevistado, pois o instrumento a ser utilizado será apenas um questionário no qual a sua identidade será mantida em sigilo.

O entrevistado está sendo convidado a participar da pesquisa, logo terá total liberdade de desistir do estudo ou retirar o seu consentimento a qualquer momento sem a necessidade de justificativas e a desistência não prejudicará sua assistência.

Portanto sua assistência será assegurada durante toda a pesquisa e lhe será garantido o livre acesso a todas as informações e esclarecimentos adicionais sobre o estudo e suas conseqüências, enfim, tudo o que o entrevistado queira saber antes, durante e depois da sua participação.

\section{Termo de Consentimento Livre e Esclarecido}

Eu declaro que, após ter sido convenientemente esclarecido, pelo pesquisador, concordei em participar do projeto de pesquisa acima.

Data

Assinatura

Endereço

(Observação: Este termo de consentimento será preenchido em duas vias sendo que uma delas deverá ficar com o 


\section{CONSENTIMENTO LIVRE E ESCLARECIDO (Espanhol)}

Datos de la investigación:

Título de la investigación: Equidad en salud: El caso de la tuberculosis en la comunidad boliviana de la ciudad de São Paulo

Investigador: Vanessa Nogueira Martinez - tel: 2942-8086

Coordenador de la investigación: Prof. Dr. Eliseu Alves Waldman - Dep. Epidemiologia da Faculdade de Saúde Pública da USP Av Dr Arnaldo 715, Cerqueira César, SP/SP-

Tel: 3061-7109

La tuberculosis es una enfermedad causada por una bacteria que se propaga por el aire y su contagio ocurre de una persona a otra al toser, estornudar o hablar en voz alta del enfermo. Normalmente esta bacteria ataca los pulmones y sus síntomas principales son tos durante más de tres semanas y la fiebre, sudores nocturnos y pérdida de peso. A pesar de ser una enfermedad curable, cuando tratada adecuadamente, y de fácil diagnóstico todavía existe muchas muertes causadas por esta enfermedad. El objetivo de este estudio es investigar algunos de los factores que pueden dificultar la cura de los pacientes, con que podremos contribuir para la mejoría en las acciones destinadas al control de la tuberculosis, facilitando la reducción de casos y muertes causados por la tuberculosis en Brasil.

Su participación en el estudio colabora con la descripción de los factores de riesgo para la tuberculosis en la comunidad boliviana de la ciudad de São Paulo, pues debido al estilo de vida de muchos inmigrantes la población es vulnerable a la enfermedad.

Este estudio podrá aportar beneficios a la comunidad de los inmigrantes en la ciudad de São Paulo, auxiliando el desarrollo de políticas públicas específicas para la mejora de acceso, el control de la enfermedad en la comunidad y mejora de la relación entre los profesionales de la salud y los inmigrantes latinoamericanos, condiciones esenciales para el tratamiento adecuado de la enfermedad. Declaro que este estudio no causa ningún incómodo o riesgo para el entrevistado, ya que el instrumento utilizado será solo un cuestionario y su identidad se mantendrá confidencial.

El entrevistado está siendo invitado a participar del estudio, tan pronto tendrá total libertad para abandonar el estudio o retirar su consentimiento en cualquier momento sin necesidad de justificación y la renuncia no afectará su atención médica.

Por lo tanto su asistencia será asegurada durante toda la investigación y se le garantido el libre acceso a toda la información y explicaciones sobre el estudio y sus consecuencias, en fin, todo lo que el entrevistado quiera saber antes, durante y después de su participación.

\section{Termo de Consentimento Livre e Esclarecido}

Yo declaro que, después de haber sido debidamente informado, por el investigador, estoy de acuerdo en participar del estudio de investigación descrito.

Fecha

Firma

Dirección 


\section{Anexo I}

\section{TERMO DE RESPONSABILIDADE}

Eu, Vanessa Nogueira Martinez, portadora do RG 27.902.385-6, me comprometo a garantir o anonimato e confidencialidade de todas as informações obtidas em Unidades Básicas de Saúde e na Coordenação de Vigilância em Saúde (COVISA) da Secretaria Municipal de Saúde de São Paulo a serem utilizadas pela pesquisa "EQUIDADE EM SAÚDE: O CASO DA TUBERCULOSE NA COMUNIDADE DE BOLIVIANOS DO MUNICÍPIO DE SÃO PAULO", tema de minha Dissertação de Mestrado a ser desenvolvida sob a orientação do Prof. Doutor Eliseu Alves Waldman, junto à Faculdade de Saúde Pública de São Paulo.

Declaro também que os dados coletados serão utilizados exclusivamente com os propósitos estabelecidos nos objetivos dessa pesquisa. Assumo a responsabilidade de divulgar seus resultados aos setores pertinentes da Secretaria Municipal de Saúde de São Paulo além de publicações científicas da área e das apresentações em eventos e/ou reuniões científicas.

Prof. Dr. Eliseu Alves Waldman

Vanessa Nogueira Martinez 


\section{Anexo II}

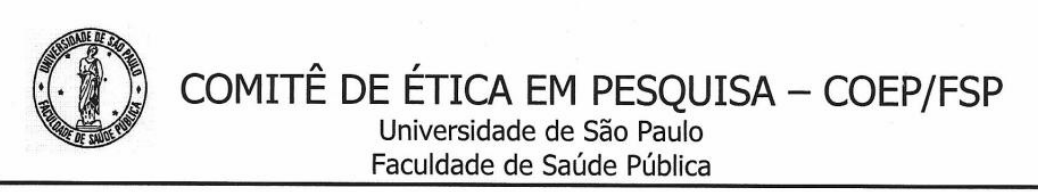

OF.COEP/321/09

São Paulo, 11 de novembro de 2009.

Prezado(a) Pesquisador(a) e Orientador(a),

o Comitê de Ética em Pesquisa da Faculdade de Saúde Pública da Universidade de São Paulo - COEP/FSP, analisou, de acordo com a Resolução N. ${ }^{\circ}$ 196/96 do Conselho Nacional de Saúde - CNS e suas complementares o protocolo de pesquisa n. ${ }^{\circ}$ 1983, intitulado "EQUIDADE EM SAÚDE: O CASO DA TUBERCULOSE NA COMUNIDADE DE BOLIVIANOS NO MUNIĆ́PIO DE SÃo PAULO", área temática GRUPO III, sob responsabilidade do(a) pesquisador(a) Vanessa Nogueira Martinez, e considera o protocolo de pesquisa acima intitulado APROVADO "AD-REFERENDUM".

Cabe lembrar que conforme Resolução CN /196/96, são deveres do (a) pesquisador (a): 1. Comunicar, de imediato, qualquer alteração no projeto e aguardar manifestação deste CEP (Comitê de Ética em Pesquisa), para dar continuidade à pesquisa; 2. Manter sob sua guarda e em local seguro, pelo prazo de 5 (cinco) anos, os dados da pesquisa, contendo fichas individuais e todos os demais documentos recomendados pelo CEP, no caso eventual auditoria; 3. Comunicar, formalmente a este Comitê, quando do encerramento deste projeto; 4. Elaborar e apresentar relatórios parciais e final; 5. Justificar, perante o CEP, interrupção do projeto ou a não publicação dos resultados.

Atenciosamente,

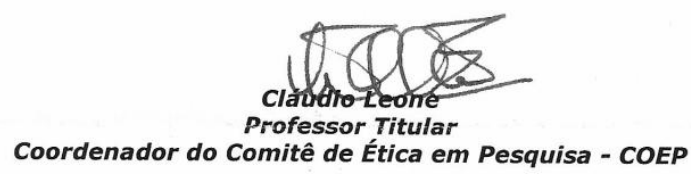

IIm. $0 \mathrm{Sr}$.

Prof. Dr. Eliseu Alves Waldman

Departamento de Epidemiologia

Faculdade de Saúde Pública - USP

Av. Dr. Arnaldo, 715 - Assessoria Acadêmica - CEP: 01246-904 - São Paulo - SP Telefones: (55-11) 3061-7779/7742 e-mail: coep@fsp.usp.br $\quad$ site www.fsp.usp.br 
OF.COEP/329/09

17 de novembro de 2009.

Prezado(a) Pesquisador(a) e Orientador(a),

o Comitê de Ética em Pesquisa da Faculdade de Saúde Pública da Universidade de São Paulo - COEP/FSP, analisou em sua 9.a/09 Sessão Extraordinária realizada em 13/11/2009, de acordo com a Resolução N. ${ }^{\circ}$ 196/96 do Conselho Nacional de Saúde - CNS e suas complementares o protocolo de pesquisa n.o 1983, intitulado "EQUIDADE EM saúde: O CASO dA tuberculose na comunidade de bolivianos No MUNICÍPIO DE SÃO PAULO", área temática GRUPO III, sob responsabilidade do(a) pesquisador(a) Vanessa Nogueira Martinez e do orientador Eliseu Alves Waldman, considerando a aprovação "ad-referendum", HOMOLOGADA.

Atenciosamente,

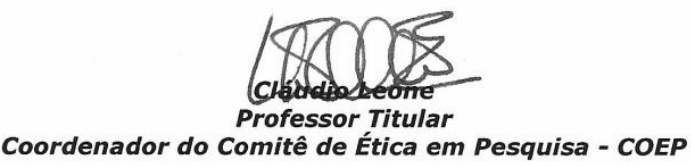

IIm. ${ }^{\circ} \mathrm{Sr}$.

Prof. Dr. Eliseu Alves Waldman

Departamento de Epidemiologia

Faculdade de Saúde Pública - USP

Av. Dr. Arnaldo, 715 - Assessoria Acadêmica - CEP: 01246-904 - São Paulo - SP Telefones: (55-11) 3061-7779/7742 e-mail: coep@fsp.usp.br site www.fsp.usp.br 


\section{Vanessa Nogueira Martinez}

Possui graduação em Ciências Biológicas pela Universidade Estadual Paulista Júlio de Mesquita Filho (2006). Tem experiência na área de epidemiologia e genética, com ênfase em Epidemiologia genética. Atualmente atua em epidemiologia de doenças reemergentes no município de São Paulo.

\section{(Texto informado pelo autor)}

Última atualização do currículo em 25/01/2010

Endereço para acessar este CV:

http://lattes.cnpq.br/0780635928929394

Certificado

pelo autor em

$25 / 01 / 10$ 


\section{Eliseu Alves Waldman}

\section{Bolsista de Produtividade em Pesquisa do CNPq - Nível 2}

Possui graduação em Medicina pela Pontifícia Universidade Católica de São Paulo (1972), residência médica em Doenças Infecciosas e Parasitárias no Hospital das Clínicas da Faculdade de Medicina da USP (1973-1976); curso de especialização em Medicina Tropical em 1974; curso de especialização em Saúde Pública pela Faculdade de Saúde Pública da Universidade de São Paulo (1975); Especialização em Administração Pública pela Fundação do Desenvolvimento Administrativo, FUNDAP (1978-1980); Curso de Especialização em Vigilância Epidemiológica (1982); mestrado em Doenças Infecciosas e Parasitárias pela Universidade de São Paulo (1982); doutorado em Saúde Pública pela Universidade de São Paulo (1991) e pós-doutorado no Departamento de Epidemiologia da School of Public Health of the Johns Hopkins University, Baltimore, EUA, como bolsista da Fundação de Amparo à Pesquisa do Estado de São Paulo (2001). Tem experiência na área de Saúde Coletiva, com foco em Epidemiologia, atuando principalmente nos seguintes temas: epidemiologia, vigilância e controle de doenças transmissíveis.

(Texto informado pelo autor)

Última atualização do currículo em 03/06/2010

Endereço para acessar este CV:

http://lattes.cnpq.br/8924923035849703 


\section{Apêndice III}

Tabela 1: Taxa de incidência* e casos de tuberculose entre bolivianos e não bolivianos nos distritos administrativos do Belém, Bom Retiro, Brás e Pari. Município de São Paulo. 1998 a 2008.

\begin{tabular}{|c|c|c|c|c|c|c|c|c|c|c|c|c|}
\hline \multirow[b]{2}{*}{ Nacionalidade } & \multicolumn{11}{|c|}{ Ano } & \multirow[b]{2}{*}{ Total } \\
\hline & 1998 & 1999 & 2000 & 2001 & 2002 & 2003 & 2004 & 2005 & 2006 & 2007 & 2008 & \\
\hline $\begin{array}{l}\text { Casos entre } \\
\text { brasileiros }\end{array}$ & 161 & 192 & 159 & 170 & 189 & 183 & 145 & 120 & 129 & 105 & 91 & 1644 \\
\hline $\begin{array}{l}\text { Casos entre } \\
\text { bolivianos }\end{array}$ & 30 & 43 & 47 & 49 & 70 & 57 & 79 & 77 & 100 & 83 & 105 & 740 \\
\hline $\begin{array}{l}\text { Casos entre outras } \\
\text { nacional. }\end{array}$ & 5 & 5 & 3 & 7 & 7 & 6 & 0 & 5 & 3 & 5 & 4 & 50 \\
\hline Total de Casos & 196 & 240 & 209 & 226 & 266 & 246 & 224 & 202 & 232 & 193 & 200 & 2434 \\
\hline Taxa de incidência* & 179,3 & 222,8 & 196,2 & 212,2 & 249,9 & 231,2 & 210,6 & 190,1 & 217,7 & 180,7 & 186,8 & \\
\hline
\end{tabular}

* Incidência por 100.000 habitantes/ano 